Federal Reserve Bank of Minneapolis

Research Department Staff Report 127/JV

\title{
Periodic Linear-Quadratic Methods for Modeling Seasonality*
}

\author{
Richard M. Todd
}

Federal Reserve Bank of Minneapolis

\begin{abstract}
Optimal linear regulator methods are used to represent a little-studied class of models of endogenous equilibrium seasonality. Seasonal structure is built into these models in two equivalent ways: periodically varying the coefficient matrices of a formerly nonseasonal problem or embedding this periodiccoefficient problem in a higher-dimensional sparse system whose time-invariant matrices have a special pattern of zero blocks. The former is compact and convenient computationally; the latter are used to apply familiar convergence results from the theory of time-invariant optimal regulator problems. The new class of seasonality models provides an equilibrium interpretation for work involving periodically stationary time series.

*The views expressed herein are those of the author and not necessarily those of the Federal Reserve Bank of Minneapolis or the Federal Reserve System.
\end{abstract}




\section{Introduction}

Seasonal fluctuations account for much of the variation in many economic time series. Moreover, theory suggests that seasonal behavior interacts in complicated ways with nonseasonal behavior [Ghysels (1988), Hansen and Sargent (1989), Manuelli and Sargent (1988)]. For these reasons, some economists have called for or proposed models that trace economic seasonality to its roots in preferences, technologies, and endowments. [See work by Ghysels (1988), Hansen and Sargent (1989), Miron and Zeldes (1988), Osborn (1988a), and Singleton (1988).]

So far, however, economic models of endogenous seasonality have been limited in important ways. Miron and Zeldes (1988) and Osborn (1988a) provide models that link seasonality, to a periodic environment (preferences, technologies, endowments); but they derive only Euler equations-not explicit decision rules or laws of motion-and the dynamic elements in their environments are relatively simple special cases. Explicit decision rules and laws of motion under fairly general specifications of dynamic constraints can, of course, be obtained from linear-quadratic (LQ) models. This LQ framework has been used to analyze how endogenous variables are affected by seasonal fluctuations in exogenous driving processes [Ghysels (1988), Sargent (1978b)]; by adjustment costs with seasonal lags [Hansen and Sargent (1989)]; and by policy feedback in the presence of seasonal filtering [Ghysels (1987)]. Except for the seasonal adjustment costs, however, the published LQ work does not focus on seasonal preferences, technologies, or endowments. Partly for that reason, it mostly deals with indeterministic seasonality, largely ignoring aspects of the environment that are anchored to a particular season.

In this article, I argue that economists have in hand the tools to explicitly model a much broader range of seasonal phenomena as equilibrium outcomes resulting from seasonal environments. First, I briefly review time-invariant LQ (TILQ) models. Then, I argue that some interesting but previously little-studied economic environments with seasonally varying preferences, technologies, or endowments can be represented using 
periodic-coefficient LQ (PLQ) frameworks just as easily as time-invariant environments are represented by standard TILQ models. Finally, I demonstrate that any PLQ model can be embedded in a higher-dimensional TILQ model with a particular pattern of zero and nonzero blocks.

This embedding has two important implications. First, it shows that the TILQ class of models contains the PLQ class. Since the PLQ class obviously contains the TILQ class, this means that any phenomenon that can be represented within one of these classes can also be represented within the other. In particular, the TILQ class can be used to represent a broader range of seasonal models than the existing literature suggests. Second, the theorems governing the convergence of decision rules and laws of motion in TILQ models can be automatically extended to PLQ models. This is important because a PLQ representation, being of much lower dimension, can be solved more efficiently on a computer than can its equivalent TILQ representation. The special forms that the key TILQ theorems assume in the PLQ case are thus useful for efficiently analyzing the convergence of PLQ decision rules and laws of motion to periodic limits.

The embedding result is developed in Section 2, with some of the details relegated to appendices. To illustrate some of the features of PLQ models, Section 3 presents a simple example of endogenous seasonality derived from seasonal shifts in technology.

\section{Periodic LQ modeling}

The general LQ class of dynamic stochastic optimization problems is characterized by the optimization of a time-varying quadratic objective subject to time-varying dynamic stochastic linear constraints. Problems in this class can be represented by the maximization, with respect to choices of feedback rules $\left\{v_{t}=-F_{t} x_{t}\right\}_{t=t_{0}}^{\left(t{ }_{1}-1\right)}$, of

$$
E_{t_{0}}\left[\sum_{t=t_{0}}^{(t}\left\{x_{t}^{-1)} R_{s(t)} x_{t}+v_{t}^{T} Q_{s(t)} v_{t}\right\}+x_{t_{1}}^{T} P_{t_{1}} x_{t_{1}}\right],
$$

subject to given values of $\mathrm{x}_{\mathrm{t}_{0}}$ and $\mathrm{P}_{\mathrm{t}_{1}}$ and to the constraint 


$$
x_{t+1}=A_{s(t)} x_{t}+B_{s(t)} v_{t}+\xi_{t+1}
$$

Here,

$s(t)$ maps the integers into an index set $J$ [for example, let $\mathrm{J}$ be the integers and let $\mathrm{s}(\mathrm{t})=\mathrm{t}]$

$$
\begin{aligned}
& \mathrm{x}_{\mathrm{t}}=\text { an } \mathrm{n} \times 1 \text { state vector } \\
& \mathrm{v}_{\mathrm{t}}=\text { an } \mathrm{m} \times 1 \text { control vector } \\
& \xi_{\mathrm{t}}=\text { an } \mathrm{n} \times 1 \text { white noise process } \\
& \mathrm{P}_{\mathrm{t}_{1}}=\text { an } \mathrm{n} \times \mathrm{n} \text { matrix } \\
& \mathrm{R}_{\mathrm{s}(\mathrm{t})}=\text { an } \mathrm{n} \times \mathrm{n} \text { matrix } \\
& \mathrm{Q}_{\mathrm{s}(\mathrm{t})}=\text { an } \mathrm{m} \times \mathrm{m} \text { matrix } \\
& \mathrm{A}_{\mathrm{s}(\mathrm{t})}=\text { an } \mathrm{n} \times \mathrm{n} \text { matrix } \\
& \mathrm{B}_{\mathrm{s}(\mathrm{t})}=\text { an } \mathrm{n} \times \mathrm{m} \text { matrix. }
\end{aligned}
$$

Under appropriate conditions, the solution to problem (1) is given by

$$
F_{t}=\left[Q_{s(t)}+B_{s(t)}^{T} P_{t+1} B_{s(t)}\right]^{-1}\left[B_{s(t)}^{T} P_{t+1} A_{s(t)}\right]
$$

where $\left[Q_{s(t)}+B_{s(t)}^{T} P_{t+1} B_{s(t)}\right]^{-1}$ is assumed to exist and $P_{t}$ satisfies

$$
\begin{aligned}
P_{t}= & R_{s(t)}+A_{s(t)}^{T} P_{t+1} A_{s(t)}-\left[A_{s(t)}^{T} P_{t+1} B_{s(t)}\right] \\
& {\left[Q_{s(t)}+B_{s(t)}^{T} P_{t+1} B_{s(t)}\right]^{-1}\left[B_{s(t)}^{T} P_{t+1} A_{s(t)}\right], }
\end{aligned}
$$

with $\mathrm{P}_{\mathrm{t}_{1}}$ given. ${ }^{1}$ [Sufficient conditions for the solution are negative semidefiniteness of $P_{t_{1}}$ and $R_{s(t)}$ and negative definiteness of $Q_{s(t)}$; see Bertsekas (1976).] 
Hansen and Sargent $(1980,1981)$ and Sargent (1981) have shown how, in a wide variety of economic models, the parameters of preferences, technologies, and endowments can be captured in the matrices $A_{s(t)}, B_{s(t)}, R_{s(t)}$, and $Q_{s(t)}$. Their results make the stochastic $L Q$ framework attractive for analyzing dynamic equilibrium in economics. The solution (2) is the dynamic programming solution; it simultaneously solves both the control and the forecasting parts of problem (1). When (1) represents an agent's dynamic optimization under uncertainty, the $F_{t}$ are the agent's optimal decision rules. When (1) represents a social planner's problem, the planner's decision rules can, in many cases, be interpreted as the laws of motion in a rational expectations competitive equilibrium of the economic aggregates. In either case, the solution links the coefficients of the decision rules $F_{t}$ to the underlying parameters of the optimization problem, $A_{s(t)}, B_{s(t)}, R_{s(t)}$, and $\mathrm{Q}_{\mathrm{s}(\mathrm{t})}$, by complicated nonlinear mappings, as has been stressed by rational expectations modelers.

In practice, most economic applications of $\mathrm{LQ}$ techniques have involved the restricted class of problems in which the matrices $\mathrm{R}, \mathrm{Q}, \mathrm{A}$, and $\mathrm{B}$ are constant over time and the horizon is assumed to be infinite. This focus is mainly because in setups with arbitrary time variation or with short horizons, agents' decision rules and the economywide laws of motion can change rapidly over time. Such rapid variation makes it difficult to check the empirical validity of the model with time-series data, either by traditional econometric means or by the calibration procedure of Kydland and Prescott (1982).

By contrast, in infinite-horizon time-invariant models, decision rules $F_{t}$ and laws of motion $\left(\mathrm{A}-\mathrm{BF}_{\mathrm{t}}\right)$ will be time-invariant and nonexplosive under certain regularity conditions. That is, $\mathrm{F}_{\mathrm{t}_{0}} \rightarrow \mathrm{F}^{*}$ and $\left(\mathrm{A}-\mathrm{BF}_{\mathrm{t}_{0}}\right) \rightarrow\left(\mathrm{A}-\mathrm{BF}^{*}\right)$ as $\mathrm{t}_{1} \rightarrow \infty$, where $\left(\mathrm{A}-\mathrm{BF}^{*}\right)$ is a stable matrix. These features make it much more practical to check the empirical validity of a model's decision rules and laws of motion with time-series data. Several applications have been reported: Christiano and Eichenbaum (1987), Eichenbaum (1984), Eckstein (1984), and Sargent (1978a) use a classical statistical approach to check empirical validity, while Kydland and Prescott (1982) use their calibration method. 
TILQ models readily accommodate some forms of seasonality, such as time-invariant driving processes whose ARMA representation implies seasonal spectral peaks or quadratic adjustment costs of the form $\left(k_{t}-k_{t-p}\right)^{2}$, where $p$ is the number of seasons per year. These are, in fact, the forms of seasonality analyzed in the TILQ models of Ghysels (1988) and Hansen and Sargent (1989).

Other interesting forms of seasonality have not been emphasized in the economics literature on TILQ models, nor are they as obviously representable within the TILQ framework. For example, consider an industry of competitive firms that choose inputs $n_{t}$ to maximize profits, subject to an industrywide demand curve that is less than perfectly elastic and to seasonal variations in the productivity of the inputs or in the demand curve. (For example, the variation might occur in consumers' marginal utility of consuming that industry's output.) Even with (time-varying) linear production and demand functions, the task of representing the industry's competitive equilibrium as a planning problem would require terms representing the interaction of the seasonal production or demand coefficients and the second power of $N_{t}$, the aggregate input. This task seems to require a PLQ rather than a TILQ model. ${ }^{2}$ That is, we need a model in which $A_{s(n p+i)}=A_{i}$, $B_{s(n p+i)}=B_{i}, R_{s(n p+i)}=R_{i}$, and $Q_{s(n p+i)}=Q_{i}$, where $p$ is the period of the seasonal cycle in the coefficients, $i \in\{1,2,3, \ldots, p\}$, and $n$ is an arbitrary integer.

Failure to represent the type of seasonality just described would be a significant drawback of the TILQ framework. One reason is that seasonal shifts in preferences and production functions are perhaps the most natural and commonly cited sources of economic seasonality. A related reason is that models which derive their seasonality from exogenous seasonal ARMA processes or from adjustment costs with seasonal lags do not readily explain the apparently common observation of seasonal phenomena containing deterministic components anchored in a particular month or quarter.

These drawbacks of the TILQ framework are only hypothetical, however. As has been long recognized in the engineering literature [Kailath (1980), p. 608], PLQ models can be rewritten as TILQ models. That point is briefly developed here by sketching how 
a PLQ model can be embedded within a higher-dimensional TILQ model. To keep the discussion concrete, I consider the case of quarterly seasonality (where $p=4$ ).

The embedding is accomplished by using two types of sparse matrices: a block diagonal matrix and what I call a periodic matrix. Let $\operatorname{diag}\left[z_{1}, z_{2}, z_{3}, z_{4}\right]$ denote the block diagonal matrix with $z_{1}, z_{2}, z_{3}, z_{4}$ as its diagonal blocks. Define the periodic matrix as $\operatorname{per}\left[z_{1}, z_{2}, z_{3}, z_{4}\right]$, where

$$
\operatorname{per}\left[z_{1}, z_{2}, z_{3}, z_{4}\right]=\left[\begin{array}{cccc}
0 & 0 & 0 & z_{4} \\
z_{1} & 0 & 0 & 0 \\
0 & z_{2} & 0 & 0 \\
0 & 0 & z_{3} & 0
\end{array}\right]
$$

Then using diag and per matrices, an LQ problem in the form of equation (1) but with quarterly variation in its coefficients can be embedded within the maximization of

$$
\begin{aligned}
& \mathrm{E}_{\mathrm{t}_{0}}\left[\sum _ { \mathrm { t } = \mathrm { t } _ { 0 } } ^ { ( \mathrm { t } _ { 1 } - 1 ) } \left[\left[\begin{array}{c}
\mathrm{x}_{1 \mathrm{t}} \\
\mathrm{x}_{2 \mathrm{t}} \\
\mathrm{x}_{3 \mathrm{t}} \\
\mathrm{x}_{4 \mathrm{t}}
\end{array}\right]^{\mathrm{T}}\left[\begin{array}{llll}
\mathrm{R}_{1} & 0 & 0 & 0 \\
0 & \mathrm{R}_{2} & 0 & 0 \\
0 & 0 & \mathrm{R}_{3} & 0 \\
0 & 0 & 0 & \mathrm{R}_{4}
\end{array}\right]\left[\begin{array}{c}
\mathrm{x}_{1 \mathrm{t}} \\
\mathrm{x}_{2 \mathrm{t}} \\
\mathrm{x}_{3 \mathrm{t}} \\
\mathrm{x}_{4 \mathrm{t}}
\end{array}\right]\right.\right. \\
& \left.+\left[\begin{array}{c}
\mathrm{v}_{1 \mathrm{t}} \\
\mathrm{v}_{2 \mathrm{t}} \\
\mathrm{v}_{3 \mathrm{t}} \\
\mathrm{v}_{4 \mathrm{t}}
\end{array}\right] \mathrm{T}\left[\begin{array}{llll}
\mathrm{Q}_{1} & 0 & 0 & 0 \\
0 & \mathrm{Q}_{2} & 0 & 0 \\
0 & 0 & \mathrm{Q}_{3} & 0 \\
0 & 0 & 0 & \mathrm{Q}_{4}
\end{array}\right]\left[\begin{array}{c}
\mathrm{v}_{1 \mathrm{t}} \\
\mathrm{v}_{2 \mathrm{t}} \\
\mathrm{v}_{3 \mathrm{t}} \\
\mathrm{v}_{4 \mathrm{t}}
\end{array}\right]\right\} \\
& \left.+\left[\begin{array}{l}
\mathrm{x}_{1 t_{1}} \\
\mathrm{x}_{2 \mathrm{t}_{1}} \\
\mathrm{x}_{3 \mathrm{t}_{1}} \\
\mathrm{x}_{4 \mathrm{t}_{1}}
\end{array}\right]^{\mathrm{T}}\left[\begin{array}{llll}
\mathrm{P}_{1 t_{1}} & 0 & 0 & 0 \\
0 & \mathrm{P}_{2 \mathrm{t}_{1}} & 0 & 0 \\
0 & 0 & \mathrm{P}_{3 \mathrm{t}_{1}} & 0 \\
0 & 0 & 0 & \mathrm{P}_{4 t_{1}}
\end{array}\right]\left[\begin{array}{l}
\mathrm{x}_{1 \mathrm{t}_{1}} \\
\mathrm{x}_{2 \mathrm{t}_{1}} \\
\mathrm{x}_{3 \mathrm{t}_{1}} \\
\mathrm{x}_{4 \mathrm{t}_{1}}
\end{array}\right]\right) .
\end{aligned}
$$


This maximization is subject to given values of $\left[\mathrm{x}_{1 \mathrm{t}_{0}}, \mathrm{x}_{2 \mathrm{t}_{0}}, \mathrm{x}_{3 \mathrm{t}_{0}}, \mathrm{x}_{4 \mathrm{t}_{0}}\right]$ and to the constraint

$$
\left[\begin{array}{l}
x_{1}{ }_{t+1} \\
x_{2} \\
x_{3_{t+1}} \\
x_{4_{t+1}}
\end{array}\right]=\left[\begin{array}{llll}
0 & 0 & 0 & A_{4} \\
A_{1} & 0 & 0 & 0 \\
0 & A_{2} & 0 & 0 \\
0 & 0 & A_{3} & 0
\end{array}\right]\left[\begin{array}{l}
x_{1 t} \\
x_{2 t} \\
x_{3 t} \\
x_{4 t}
\end{array}\right]+\left[\begin{array}{llll}
0 & 0 & 0 & B_{4} \\
B_{1} & 0 & 0 & 0 \\
0 & B_{2} & 0 & 0 \\
0 & 0 & B_{3} & 0
\end{array}\right]\left[\begin{array}{c}
v_{1 t} \\
v_{2 t} \\
v_{3 t} \\
v_{4 t}
\end{array}\right]+\left[\begin{array}{l}
\xi_{1 t} \\
\xi_{2 t} \\
\xi_{3 t} \\
\xi_{4 t}
\end{array}\right] .
$$

Here, the maximization is over feedback rules of the form

$$
\left[\begin{array}{c}
\mathrm{v}_{1 \mathrm{t}} \\
\mathrm{v}_{2 \mathrm{t}} \\
\mathrm{v}_{3 \mathrm{t}} \\
\mathrm{v}_{4 \mathrm{t}}
\end{array}\right]=-\left[\begin{array}{llll}
\mathrm{F}_{1 \mathrm{t}} & 0 & 0 & 0 \\
0 & \mathrm{~F}_{2 \mathrm{t}} & 0 & 0 \\
0 & 0 & \mathrm{~F}_{3 \mathrm{t}} & 0 \\
0 & 0 & 0 & \mathrm{~F}_{4 t}
\end{array}\right]\left[\begin{array}{c}
\mathrm{x}_{1 \mathrm{t}} \\
\mathrm{x}_{2 \mathrm{t}} \\
\mathrm{x}_{3 \mathrm{t}} \\
\mathrm{x}_{4 \mathrm{t}}
\end{array}\right]
$$

In the TILQ form of the system, each $x_{i t}, v_{i t}, R_{i}, Q_{i}, A_{i}, B_{i}, F_{i}$, and $\xi_{i t}$ has the same dimension as $x_{t}, v_{t}, R_{t}, Q_{t}, A_{t}, B_{t}, F_{t}$, and $\xi_{t}$, respectively, in the original system. That is, the new TILQ system's state space is ( $p=$ ) 4 times larger than the PLQ model's state space. At any time $t$, in fact, only one component of the TILQ model's state space corresponds to $x_{t}$ in the $P L Q$ problem. (The other three components can be thought of as representing independent, parallel universes whose economic structure is identical except for a 1-, 2-, or 3-quarter phase shift in the seasonal variation of the environment.) The component that corresponds to $x_{t}$ from the TILQ problem cycles through the four positions of the PLQ state vector, thanks to the periodic structure of the A and $B$ matrices. As that component cycles through the four positions, it interacts sequentially with the four sets of seasonal coefficients in the PLQ problem.

Appendix A details how this higher-dimensional TILQ problem embeds the PLQ problem. In particular, the appendix shows how the decision rules $F_{t}$ of the periodic 
problem converge in the limit (as $t_{1} \rightarrow \infty$ ) to the periodic sequence $\left[\ldots \mathrm{F}_{1}, \mathrm{~F}_{2}, \mathrm{~F}_{3}, \mathrm{~F}_{4}, \mathrm{~F}_{1}, \mathrm{~F}_{2}, \mathrm{~F}_{3}, \mathrm{~F}_{4}, \ldots\right]$ whose distinct elements make up the limit, $\operatorname{diag}\left[\mathrm{F}_{1}, \mathrm{~F}_{2}, \mathrm{~F}_{3}, \mathrm{~F}_{4}\right]$, of the higher-dimensional TILQ decision rule.

Embedding the PLQ problem within a TILQ problem shows that any type of seasonality that can be modeled with the former can also be modeled with the latter. The reverse is obviously true. Since the extensive TILQ literature provides many theorems for analyzing the limiting behavior of TILQ systems, it initially seems convenient to use the TILQ form over the PLQ form. This would come at a computational cost, however, given the much higher dimensionality of the TILQ system.

Not surprisingly, this computational burden need not be incurred. The higher-dimensional TILQ form of a PLQ model is useful not for numerical computation but rather as a device for extending to PLQ models the TILQ theorems on convergence. (See Appendix B for a summary of some useful periodic versions of TILQ theorems.) These theorems tell when $F_{t_{0}+i} \rightarrow F_{i}^{*}$ and $\left[A_{i}-B_{i} F_{t_{0}+i}\right] \rightarrow\left[A_{i}-B_{i} F_{i}^{*}\right]$ as $t_{1} \rightarrow$ w and $i=$ $1,2,3,4$. The theorems also tell when the set of matrices $\left\{\left[A_{i}-B_{i} F_{i}^{*}\right], i=1,2,3,4\right\}$ that govern the reduced-form or closed-loop evolution of the system implies nonexplosive behavior. With nonexplosive behavior, the system $X_{4 n+i+1}=\left[A_{i}-B_{i} F_{i}\right] X_{4 n+i}+$ $\xi_{4 n+i+1}$, which governs the evolution of the state variables during the $i^{\text {th }}$ quarter of the $\mathrm{n}^{\text {th }}$ year (for $\mathrm{i}=1,2,3,4$ and $\mathrm{n}=\mathrm{n}_{0}, \mathrm{n}_{0}+1, \mathrm{n}_{0}+2, \ldots$ ), can be modeled as periodically stationary. (That is, the system's $\tau^{\text {th }}$-order covariances depend on $\tau$ and $\mathrm{i}$, but not on n.) Convergent, nonexplosive models of seasonality can be quantitatively analyzed by essentially the same means, and with nearly the same ease, as their more standard TILQ counterparts. ${ }^{3}$

\section{An example: Input demand with seasonal productivity}

To highlight the main features of a PLQ model, consider the following stripped-down but periodic version of Sargent's (1987, pp. 402-4) LQ representation of the Lucas and 
Prescott (1971) investment model. Let there be $\mathbf{n}$ identical, price-taking firms seeking to maximize the present value of their expected profits. Each quarter, the firms face the time-invariant, downward-sloping industry demand curve

$$
\mathrm{P}_{\mathrm{t}}=\alpha_{0}-\alpha_{1} \mathrm{Y}_{\mathrm{t}}+\mathrm{u}_{\mathrm{t}}
$$

where $P_{t}$ is price and $Y_{t}=n y_{t}$, with $y_{t}$ the output of the representative firm. The demand shock $u_{t}$ is generated by the stationary AR(1) process

$$
\mathrm{u}_{\mathrm{t}}=\rho \mathrm{u}_{\mathrm{t}-1}+\xi_{\mathrm{t}+1}
$$

where $\xi_{\mathrm{t}}$ is iid as $\mathrm{N}\left(0, \sigma_{\xi}^{2}\right)$. The representative firm can produce output according to

$$
y_{t}=f_{t} k_{t}
$$

where $k_{t}$ is the firm's input (capital) and $f_{t}$ is the productivity of capital. Productivity, assumed to be perfectly periodic $\left(f_{t}=f_{t+4}\right.$, for all $\left.t\right)$, is the model's only source of seasonality. The firm also incurs costs equal to

$$
\mathrm{rk}_{\mathrm{t}}-(\delta / 2)\left[\mathrm{k}_{\mathrm{t}+1}-\mathrm{k}_{\mathrm{t}}\right]^{2},
$$

where $\mathrm{r}$ is the (nonstochastic) rental cost of capital and $\delta$ penalizes changes in the input use. Finally, the firm applies the discount factor $b(0<b<1)$ to future profits.

As shown by Sargent (1987, p. 402), competitive partial equilibrium for the industry can be found as the solution to the social planning problem of maximizing the following objective

$$
\begin{gathered}
E_{t}\left[\sum _ { j = 0 } ^ { \infty } b ^ { j } \left\{\alpha_{0} f_{t+j} K_{t+j}-\left[\alpha_{1} f_{t+j}^{2} / 2\right] K_{t+j}^{2}+f_{t+j} u_{t+j} K_{t+j}\right.\right. \\
\left.\left.-r K_{t+j}-[\delta /(2 n)]\left[K_{t+j+1}-K_{t+j}\right]^{2}\right\}\right],
\end{gathered}
$$

with respect to decision rules for choosing $\mathrm{k}_{\mathrm{t}+1}$ after observing $\mathrm{k}_{\mathrm{t}}$ and $\mathrm{u}_{\mathrm{t}}$. Here, $\mathrm{K}_{\mathrm{t}}=$ $n k_{t}$, and $K_{0}, u_{0}, u_{-1}, u_{-2}, \ldots$ are given. Converting this problem into the form of equation (1) requires driving $t_{1} \rightarrow \infty$ and setting 


$$
\begin{aligned}
& x_{t_{0}+j}^{T}=b^{j / 2}\left[k_{t_{0}+j}, u_{t_{0}+j}, 1\right] \\
& v_{t_{0}+j}=b^{j / 2}\left[K_{t_{0}+j+1}-K_{t_{0}+j}\right] \text {, } \\
& A_{t}=A=b^{1 / 2}\left[\begin{array}{lll}
1 & 0 & 0 \\
0 & \rho & 0 \\
0 & 0 & 1
\end{array}\right], \\
& \mathrm{B}_{\mathrm{t}}=\mathrm{B}=\mathrm{b}^{1 / 2}\left[\begin{array}{l}
1 \\
0 \\
0
\end{array}\right] \text {, } \\
& R_{t}=\left[\begin{array}{lcc}
-\alpha_{1} f_{t}^{2} / 2 & f_{t} / 2 & \left(\alpha_{0} f_{t}-r\right) / 2 \\
f_{t} / 2 & 0 & 0 \\
\left(\alpha_{0} f_{t}-r\right) / 2 & 0 & 0
\end{array}\right] \\
& \mathrm{Q}_{\mathrm{t}}=\mathrm{Q}=-[\delta /(2 \mathrm{n})]
\end{aligned}
$$

The solution to this planning problem is computed recursively by applying the formulas (2) until the $\mathrm{F}_{\mathrm{t}}$ sequence converges to its periodic limit. These formulas generate a numerical-not an analytical-solution, so the model must be parameterized. Consider the following values for

Demand: $\quad \alpha_{0}=8, . \alpha_{1}=1, \rho=0.95, \sigma_{\xi}^{2}=0.5$

Productivity: $\quad f_{t}=2$ in spring and $f_{t}=1$ otherwise

Costs: $\quad \mathrm{r}=4, \delta=500$

Other: $\quad \mathrm{n}=1,000, \mathrm{~b}=0.995$.

The model is thus time-invariant except that productivity is high in the spring.

For the parameter values (9), the coefficients of the $\mathrm{F}_{\mathrm{t}}$ matrices converge, in the sense that $\left|\mathrm{F}_{\mathrm{t}}-\mathrm{F}_{\mathrm{t}-4}\right|<0.00000001$ after 20 iterations on equation (2), to the following seasonal decision rules for time $s=t_{0}+j$ : 
Winter: $\quad \mathrm{b}^{-\mathrm{j} / 2} \mathrm{v}_{\mathrm{s}}=\left[\mathrm{k}_{\mathrm{s}+1}-\mathrm{k}_{\mathrm{s}}\right]=2.76-(0.90) \mathrm{k}_{\mathrm{s}}+(0.46) \mathrm{u}_{\mathrm{s}}$

Spring: $\quad \mathrm{b}^{-\mathrm{j} / 2} \mathrm{v}_{\mathrm{s}}=\left[\mathrm{k}_{\mathrm{s}+1}-\mathrm{k}_{\mathrm{s}}\right]=2.91-(0.73) \mathrm{k}_{\mathrm{s}}+(0.68) \mathrm{u}_{\mathrm{s}}$

Summer: $\quad \mathrm{b}^{-\mathrm{j} / 2} \mathrm{v}_{\mathrm{s}}=\left[\mathrm{k}_{\mathrm{s}+1}-\mathrm{k}_{\mathrm{s}}\right]=2.87-(0.73) \mathrm{k}_{\mathrm{s}}+(0.66) \mathrm{u}_{\mathrm{s}}$

Fall:

$$
\mathrm{b}^{-\mathrm{j} / 2} \mathrm{v}_{\mathrm{s}}=\left[\mathrm{k}_{\mathrm{s}+1}-\mathrm{k}_{\mathrm{s}}\right]=2.76-(0.74) \mathrm{k}_{\mathrm{s}}+(0.60) \mathrm{u}_{\mathrm{s}} \text {. }
$$

Substituting these decision rules and parameter values into $\mathrm{A}, \mathrm{B}$, and $\mathrm{F}_{\mathrm{t}}^{*}$ and canceling terms in $b$ gives the following seasonally varying reduced-form or closed-loop system for the industry:

Winter: $\quad\left[\begin{array}{l}\mathrm{K}_{\mathrm{t}+1} \\ \mathrm{u}_{\mathrm{t}+1} \\ 1\end{array}\right]=\left[\begin{array}{lll}0.10 & 0.46 & 2.76 \\ 0.00 & 0.95 & 0.00 \\ 0.00 & 0.00 & 1.00\end{array}\right]\left[\begin{array}{l}\mathrm{K}_{\mathrm{t}} \\ \mathrm{u}_{\mathrm{t}} \\ 1\end{array}\right]+\left[\begin{array}{l}0 \\ \xi_{\mathrm{t}+1} \\ 0\end{array}\right]$

Spring: $\quad\left[\begin{array}{l}\mathrm{K}_{\mathrm{t}+1} \\ \mathrm{u}_{\mathrm{t}+1} \\ 1\end{array}\right]=\left[\begin{array}{lll}0.27 & 0.68 & 2.91 \\ 0.00 & 0.95 & 0.00 \\ 0.00 & 0.00 & 1.00\end{array}\right]\left[\begin{array}{l}\mathrm{K}_{\mathrm{t}} \\ \mathrm{u}_{\mathrm{t}} \\ 1\end{array}\right]+\left[\begin{array}{l}0 \\ \xi_{\mathrm{t}+1} \\ 0\end{array}\right]$

Summer: $\left[\begin{array}{l}\mathrm{K}_{\mathrm{t}+1} \\ \mathrm{u}_{\mathrm{t}+1} \\ 1\end{array}\right]=\left[\begin{array}{lll}0.27 & 0.66 & 2.87 \\ 0.00 & 0.95 & 0.00 \\ 0.00 & 0.00 & 1.00\end{array}\right]\left[\begin{array}{l}\mathrm{K}_{\mathrm{t}} \\ \mathrm{u}_{\mathrm{t}} \\ 1\end{array}\right]+\left[\begin{array}{l}0 \\ \xi_{\mathrm{t}+1} \\ 0\end{array}\right]$

Fall: $\quad\left[\begin{array}{l}\mathrm{K}_{\mathrm{t}+1} \\ \mathrm{u}_{\mathrm{t}+1} \\ 1\end{array}\right]=\left[\begin{array}{lll}0.26 & 0.60 & 2.87 \\ 0.00 & 0.95 & 0.00 \\ 0.00 & 0.00 & 1.00\end{array}\right]\left[\begin{array}{l}\mathrm{K}_{\mathrm{t}} \\ \mathrm{u}_{\mathrm{t}} \\ 1\end{array}\right]+\left[\begin{array}{l}0 \\ \xi_{\mathrm{t}+1} \\ 0\end{array}\right]$.

To illustrate the time-series properties of the reduced-form system, I generated an initial set of 6,000 quarters of draws of $\xi_{t}{ }^{4}$ These were used, along with the system (11) and initial values of zero for $u_{t}$ and $K_{t}$, to compute a 6,000-quarter time series for $K_{t}$ and $u_{t}$. Under the assumption that the system was oscillating near its steady state after 6,000 periods, the values of $K$ and $u$ in quarter 6,000 were then passed as initial values to generate an additional 256 quarters of data on $K_{t}, u_{t}, P_{t}$, and $Y_{t}$. Fig. 1 shows that, over a 128-quarter subsample, the driving process $u_{t}$ is highly persistent and that this persistence is transmitted to $K_{t}$ and $Y_{t}$ and transmitted slightly to $P_{t}$. Figs. 1 and 2 
each show that the three endogenous series also have clear seasonal fluctuations, despite the absence of seasonal power in the logged periodogram of the AR(1) driving process. ${ }^{5}$

The seasonality in the endogenous series is anchored to specific seasons. Prices tend to be lowest and output highest in the spring, when the productivity peak halves (static) marginal costs. The seasonal pattern in the input use is less obvious, because the higher productivity in the spring tends to both expand output (by lowering static marginal costs) and reduce the amount of input needed per unit of output. In this case, the latter effect is slightly dominant, so capital tends to have a mild seasonal dip in the spring.

In fact, capital tends to dip in the spring as long as its rental cost is below $5^{1 / 3}$ (assuming other parameters remain as specified). At higher rental costs, the average output price is far enough into the elastic region of the demand curve to give capital, on average, a springtime peak. In other words, in this model a change in the average level of a nonseasonal exogenous series can amplify, mute, or even reverse the seasonal pattern in an endogenous series. This possibility provides a simple economic interpretation for the phenomenon of changing seasonal patterns, which is often encountered by practitioners of seasonal adjustment.

The sharp spikes in the logged periodograms of $K_{t}, Y_{t}$, and $P_{t}$ suggest that, at least in this simple example, their seasonality might be captured well by seasonal dummies. To give a sense in which this might be true, I used the 256 data points and ordinary least squares to estimate the following equation:

$$
\mathrm{K}_{\mathrm{t}+1}=\underset{(0.03)}{0.11 \mathrm{~K}_{\mathrm{t}}}+\underset{(0.02)}{0.68 \mathrm{u}_{\mathrm{t}}}+\underset{(0.10)}{3.43 \mathrm{Q}_{1}}+\underset{(0.12)}{2.68 \mathrm{Q}_{2}}+\underset{(0.12)}{3.35 \mathrm{Q}_{3}}+\underset{(0.12)}{3.49 \mathrm{Q}_{4}}
$$

where $Q_{i}$ is 1 in the $i^{\text {th }}$ quarter and zero otherwise. (The fitted equation has an $R^{2}$ of 0.97 , a Durbin-Watson statistic of 2.38 , and a $\mathrm{Q}$-statistic that strongly rejects the hypothesis of no serial correlation. Standard errors of the coefficients are shown in parentheses.) 
Note that the coefficients on lagged $\mathrm{K}_{t}$ and $\mathrm{u}_{\mathrm{t}}$ recovered by this regression, though bounded by the corresponding values in the closed-loop system, lie near the boundary. Fig. 3 shows that the response of the system defined by (12) to a unit shock in $u_{t}$ captures fairly well the gross characteristics (average height, early peak, and overall downward slope) of the seasonal impulse response functions for the system (11). However, the impulse response of system (12) completely obscures the seasonal oscillations within each of the four impulse response functions of system (11). For example, the first period of the impulse response of the time-invariant system is about 50 percent higher than the first period of the true response to a first-quarter shock. In this example, then, the adequacy of the approximation (12) to the system (11) depends on whether the seasonal details of the true impulse responses are important for analyzing a particular problem.

A time-invariant system, however, will not always capture the gross characteristics of the true seasonal impulse responses as adequately as in this example. In Todd's (1983) empirically calibrated agricultural model, impulse responses to a given shock sometimes differ significantly in average magnitude from month to month or even change signs. No single time-invariant impulse response can summarize such behavior.

\section{Concluding remarks}

New models of purely endogenous economic seasonality can be formulated and analyzed by means of $\mathrm{LQ}$ problems with periodic-coefficient matrices. These models can represent phenomena, such as seasonal shifts in production or utility functions, that are accommodated in TILQ models only by greatly expanding the system's dimension. Nonetheless, the PLQ problem can be solved by convenient recursive algorithms. The limiting properties of its solution, as the horizon goes to infinity, are governed by natural generalizations of well-known theorems developed for TILQ problems.

One possible application of PLQ models is to examine whether the theoretical nonseparability of seasonal and nonseasonal dynamics is quantitatively important. As 
noted earlier, TILQ problems have already been used to empirically analyze a variety of models and hypotheses. In general, these analyses use either annual or seasonally adjusted data or derive their seasonality from exogenous price series whose seasonality is unexplained. Repeating these studies with allowance for deterministic seasonality in preferences, technologies, and endowments would not greatly increase the quantitative work load, provided the appropriate data are available. Such an exercise would show how much is lost in these models because of the assumptions that seasonal movements can be either ignored, adjusted for, or taken as exogenous. Todd's (1983) partially calibrated monthly model of the U.S. corn, soybean, and hog sectors provides an empirical example in which the responses to policy shocks differ significantly depending on the season in which the shocks occur.

PLQ models are also potentially useful for interpreting work on periodic-coefficient time-series models in economics. Time-series models with periodic coefficients have been studied from time to time [by Pesando (1972), Gersovitz and MacKinnon (1978), Parzen and Pagano (1979), and Trivedi and Lee (1981)]. Interest in these models may revive as a result of recent work by Osborn (1988a,b) and her associates [Osborn and Smith (1989), Birchenhall et al. (1988)]. Their work suggests that periodic-coefficient time-series models can achieve modest improvements in out-of-sample forecasts for some economic series. PLQ models supplement periodic-coefficient time-series models by showing explicitly how these time-series models can arise as equilibrium reduced-form equations. 


\section{Notes}

${ }^{*}$ I thank Larry Christiano, Warren Weber, and especially Tom Sargent for encouragement and advice. Careful reviews by two anonymous referees also refined my understanding of the topics covered here. I take full responsibility for the paper's defects. The views expressed herein are my own and not necessarily those of the Federal Reserve Bank of Minneapolis or the Federal Reserve System.

'Problems with a discount factor $b$ can be transformed into problem (1). The required transformation of variables is accomplished basically by substituting $\bar{x}_{t}=b^{t / 2} x_{t}$ for $x_{t}$ and $\tilde{v}_{t}=b^{t / 2} v_{t}$ for $v_{t}$ and absorbing a factor of $b^{1 / 2}$ in $A_{s(t)}$ and $B_{s(t)}$. See Sargent (1981) or the example in Section 3.

${ }^{2}$ Strictly speaking, stochastic variation in the seasonal coefficients cannot be accommodated. It might, however, be approximated reasonably accurately via a PLQ Taylor-series approximation.

${ }^{3}$ Instead of the recursive numerical solution techniques discussed here, some TILQ applications use calculus-of-variations techniques to derive analytic; or nearly analytic, solutions. These analytic solutions are useful for qualitative or theoretical analysis because they show the functional form of the relationships between parameters of agents' optimization problems (the elements of their R, Q, A, and B matrices) and coefficients in agents' decision rules or the reduced-form equations for endogenous variables. Analytic solutions are also handy for quantitative analysis, for they considerably speed up computation of the likelihoods or equilibrium time paths associated with a given set of decision problem parameters. These calculus-of-variations techniques can also be generalized to a broad class of PLQ problems [see Todd $(1982,1987)]$.

${ }^{4}$ The normal random-number generator used here transforms a uniform distribution into a normal distribution. The uniform distribution is based on the multiplicative-congruential method discussed by Kennedy and Gentle (1980, pp. 136-47). The transformation to normal is based on the fast acceptance-rejection algorithm 
discussed by Kinderman and Ramage (1976). The entire procedure was carried out via the RNDN command of the GAUSS software package, Version 1.49.

${ }^{5}$ The spectra in fig. 2 were computed from data series of length 4,000 that were generated as described in the text. 


\section{Appendix A}

An equivalence between periodic and time-invariant LQ problems

The strategy for extending the TILQ convergence theorems to the PLQ case is to rewrite the PLQ problem as a TILQ problem with a higher-dimensional state space. Once this is done, Appendix B shows that well-known time-invariant results have convenient PLQ versions.

The PLQ problem is obtained from equation (1) by setting $s(t)=s(t+p)$, for all $t$ and a given integer $p$ that specifies the period of the deterministic cycles in $R, Q, A$, and B. In the quarterly framework adopted in this paper, for example, $s(t)=m_{4}(t)$, where $m_{p}(t)$ is $p$ if $t$ is evenly divisible by $p$ and is otherwise the integer remainder from dividing $t$ by $p$. In addition, assume that the calendar is aligned so that $s(t)=1,2,3$, and 4 in quarters $1,2,3$, and 4 , respectively.

To rewrite the periodic version of problem (1), embed its periodic parameter matrices in some larger but sparse matrices. In particular, let

$$
\begin{aligned}
& \mathrm{Q}=\operatorname{diag}\left[\mathrm{Q}_{\mathrm{s}(1)}, \mathrm{Q}_{\mathrm{s}(2)}, \mathrm{Q}_{\mathrm{s}(3)}, \mathrm{Q}_{\mathrm{s}(4)}\right] \equiv \operatorname{diag}\left[\mathrm{Q}_{1}, \mathrm{Q}_{2}, \mathrm{Q}_{3}, \mathrm{Q}_{4}\right] \\
& \mathrm{R}=\operatorname{diag}\left[\mathrm{R}_{\mathrm{s}(1)}, \mathrm{R}_{\mathrm{s}(2)}, \mathrm{R}_{\mathrm{s}(3)}, \mathrm{R}_{\mathrm{s}(4)}\right] \equiv \operatorname{diag}\left[\mathrm{R}_{1}, \mathrm{R}_{2}, \mathrm{R}_{3}, \mathrm{R}_{4}\right] \\
& \mathrm{K}_{\mathrm{t}_{1}}=\operatorname{diag}\left[\mathrm{K}_{\mathrm{t}_{1}}^{1}, \mathrm{~K}_{\mathrm{t}_{1}}^{2}, \mathrm{~K}_{\mathrm{t}_{1}}^{3}, \mathrm{~K}_{\mathrm{t}_{1}}^{4}\right] \\
& \mathrm{y}_{\mathrm{t}}=\left[\delta_{1 \mathrm{t}} \mathrm{x}_{\mathrm{t}}^{\mathrm{T}}, \delta_{2 \mathrm{t}} \mathrm{x}_{\mathrm{t}}^{\mathrm{T}}, \delta_{3 \mathrm{t}} \mathrm{x}_{\mathrm{t}}^{\mathrm{T}}, \delta_{4 t} \mathrm{x}_{\mathrm{t}}^{\mathrm{T}}\right] \mathrm{T}
\end{aligned}
$$

where diag $\left[\mathrm{Z}_{1}, \mathrm{Z}_{2}, \ldots, \mathrm{Z}_{\mathrm{p}}\right]$ denotes a diagonal (or block diagonal) matrix with diagonal elements $\mathrm{Z}_{1}, \mathrm{Z}_{2}, \ldots, \mathrm{Z}_{\mathrm{p}} ; \mathrm{K}_{\mathrm{t}_{1}}^{\mathrm{i}}=\mathrm{P}_{\mathrm{t}_{1}}$, for $\mathrm{i}=1,2,3,4$; and $\delta_{\mathrm{it}}=1$ if $\mathrm{i}=\mathrm{m}_{4}(\mathrm{t})$ and 0 otherwise. Thus $\mathrm{Q}$ is a $4 \mathrm{~m} \times 4 \mathrm{~m}$ symmetric negative definite matrix, and $\mathrm{R}$ and $\mathrm{K}_{\mathrm{t}_{1}}$ are $4 \mathrm{n} \times 4 \mathrm{n}$ symmetric negative semidefinite matrices. Also form 


$$
\begin{aligned}
& A=\operatorname{per}\left[A_{s(1)}, A_{s(2)}, A_{s(3)}, A_{s(4)}\right] \equiv \operatorname{per}\left[A_{1}, A_{2}, A_{3}, A_{4}\right] \\
& B=\operatorname{per}\left[B_{s(1)}, B_{s(2)}, B_{s(3)}, B_{s(4)}\right] \equiv \operatorname{per}\left[B_{1}, B_{2}, B_{3}, B_{4}\right]
\end{aligned}
$$

where

$$
\operatorname{per}\left[\mathrm{Z}_{1}, \mathrm{Z}_{2}, \mathrm{Z}_{3}, \mathrm{Z}_{4}\right]=\left[\begin{array}{cccc}
0 & 0 & 0 & \mathrm{Z}_{4} \\
\mathrm{Z}_{1} & 0 & 0 & 0 \\
0 & \mathrm{Z}_{2} & 0 & 0 \\
0 & 0 & \mathrm{Z}_{3} & 0
\end{array}\right] \text {. }
$$

Finally, for all integers $\mathrm{k}$, let $\mathrm{e}_{\mathrm{s}(\mathrm{t})}=\left[\delta_{1 \mathrm{t}} \mathrm{I}, \delta_{2 \mathrm{t}} \mathrm{I}, \delta_{3 \mathrm{t}} \mathrm{I}, \delta_{4 \mathrm{t}} \mathrm{I}\right] \mathrm{T}$, where $\delta_{\mathrm{it}}$ is defined above and $\mathrm{I}$ is the $\mathrm{n} \times \mathrm{n}$ identity matrix.

I now show that problem (1) can be reexpressed as choosing feedback rules $\left\{u_{t}=-\mathrm{L}_{t} \mathrm{y}_{\mathrm{t}}\right\}_{\mathrm{t}=\mathrm{t}_{0}}^{\left(\mathrm{t}_{1}-1\right)}$ to maximize

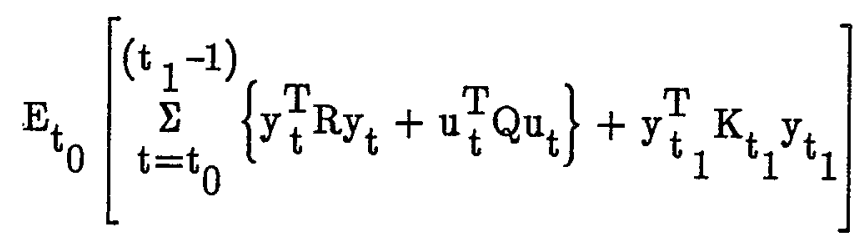

subject to the given values of $\mathrm{y}_{\mathrm{t}_{0}}$ and $\mathrm{K}_{\mathrm{t}_{1}}$ and to the constraint

$$
y_{t+1}=A y_{t}+B u_{t}+e_{s(t+1)} \xi_{t+1}
$$

This problem is essentially time-invariant because time-varying parameters appear only in the matrices $e_{s(t)}$. Due to certainty equivalence, these matrices don't affect the optimal feedback matrices $\mathrm{L}_{t}$ or the optimized-value matrices $\mathrm{K}_{\mathrm{t}}$. A slight reinterpretation of these results can be added later to allow $e_{s(t)}$ to be the $4 n \times 4 n$ identity matrix, making the system completely time-invariant. As a result, the solutions to the finite-horizon problem (1) and the many theorems concerning the limiting behavior of time-invariant $\mathrm{LQ}$ problems can be transferred wholesale to this rewritten version of the periodic LQ problem. 
Standard LQ methods solve problem (A.1) by first computing a sequence of value matrices according to

$$
\begin{aligned}
K_{\left(t_{1}-k\right)} & =R+A^{T}\left[K_{\left(t_{1}-k+1\right)}\right. \\
& \left.-K_{\left(t_{1}-k+1\right)} B\left[Q+B^{T_{K}}{\left(t_{1}-k+1\right)}^{B}\right]^{-1} B^{T} K_{\left(t_{1}-k+1\right)}\right] A .
\end{aligned}
$$

Showing how this $K$ sequence relates to the $P$ sequence used to solve problem (1) is the key to showing that problems (1) and (A.1) are equivalent. The following results, which can be checked directly, simplify the analysis (let all variables in this expression represent matrices and assume that all matrices to be multiplied are conformable):

$$
\begin{aligned}
& {\left[\operatorname{per}\left[\mathrm{X}_{1}, \mathrm{X}_{2}, \mathrm{X}_{3}, \mathrm{X}_{4}\right]\right]^{\mathrm{T}} \operatorname{diag}\left[\mathrm{Z}_{1}, \mathrm{Z}_{2}, \mathrm{Z}_{3}, \mathrm{Z}_{4}\right]=\left[\operatorname{per}\left[\mathrm{Z}_{2}^{\mathrm{T}} \mathrm{X}_{1}, \mathrm{Z}_{3}^{\mathrm{T}} \mathrm{X}_{2}, \mathrm{Z}_{4}^{\mathrm{T}} \mathrm{X}_{3}, \mathrm{Z}_{1}^{\mathrm{T}} \mathrm{X}_{4}\right]\right]^{\mathrm{T}}} \\
& {\left[\operatorname{diag}\left[\mathrm{Z}_{1}, \mathrm{Z}_{2}, \mathrm{Z}_{3}, \mathrm{Z}_{4}\right]\right]^{\mathrm{T}} \operatorname{per}\left[\mathrm{X}_{1}, \mathrm{X}_{2}, \mathrm{X}_{3}, \mathrm{X}_{4}\right]=\operatorname{per}\left[\mathrm{Z}_{2}^{\mathrm{T}} \mathrm{X}_{1}, \mathrm{Z}_{3}^{\mathrm{T}} \mathrm{X}_{2}, \mathrm{Z}_{4}^{\mathrm{T}} \mathrm{X}_{3}, \mathrm{Z}_{1}^{\mathrm{T}} \mathrm{X}_{4}\right]} \\
& {\left[\operatorname{per}\left[\mathrm{X}_{1}, \mathrm{X}_{2}, \mathrm{X}_{3}, \mathrm{X}_{4}\right]\right]^{\mathrm{T}} \operatorname{per}\left[\mathrm{Y}_{1}, \mathrm{Y}_{2}, \mathrm{Y}_{3}, \mathrm{Y}_{4}\right]=\operatorname{diag}\left[\mathrm{X}_{1}^{\mathrm{T}} \mathrm{Y}_{1}, \mathrm{X}_{2}^{\mathrm{T}} \mathrm{Y}_{2}, \mathrm{X}_{3}^{\mathrm{T}} \mathrm{Y}_{3}, \mathrm{X}_{4}^{\mathrm{T}} \mathrm{Y}_{4}\right]} \\
& \operatorname{per}\left[\mathrm{X}_{1}, \mathrm{X}_{2}, \mathrm{X}_{3}, \mathrm{X}_{4}\right]\left[\operatorname{per}\left[\mathrm{Y}_{1}, \mathrm{Y}_{2}, \mathrm{Y}_{3}, \mathrm{Y}_{4}\right]\right]^{\mathrm{T}}=\operatorname{diag}\left[\mathrm{X}_{4} \mathrm{Y}_{4}^{\mathrm{T}}, \mathrm{X}_{1} \mathrm{Y}_{1}^{\mathrm{T}}, \mathrm{X}_{2} \mathrm{Y}_{2}^{\mathrm{T}}, \mathrm{X}_{3} \mathrm{Y}_{3}^{\mathrm{T}}\right] \\
& \operatorname{per}\left[\mathrm{X}_{1}, \mathrm{X}_{2}, \mathrm{X}_{3}, \mathrm{X}_{4}\right]\left[\operatorname{diag}\left[\mathrm{Z}_{1}, \mathrm{Z}_{2}, \mathrm{Z}_{3}, \mathrm{Z}_{4}\right]\right]^{\mathrm{T}}=\operatorname{per}\left[\mathrm{X}_{1} \mathrm{Z}_{1}^{\mathrm{T}}, \mathrm{X}_{2} \mathrm{Z}_{2}^{\mathrm{T}}, \mathrm{X}_{3} \mathrm{Z}_{3}^{\mathrm{T}}, \mathrm{X}_{4} \mathrm{Z}_{4}^{\mathrm{T}}\right] \\
& \operatorname{diag}\left[\mathrm{Z}_{1}, \mathrm{Z}_{2}, \mathrm{Z}_{3}, \mathrm{Z}_{4}\right]\left[\operatorname{per}\left[\mathrm{X}_{1}, \mathrm{X}_{2}, \mathrm{X}_{3}, \mathrm{X}_{4}\right]\right]^{\mathrm{T}}=\left[\operatorname{per}\left[\mathrm{X}_{1} \mathrm{Z}_{1}^{\mathrm{T}}, \mathrm{X}_{2} \mathrm{Z}_{2}^{\mathrm{T}}, \mathrm{X}_{3} \mathrm{Z}_{3}^{\mathrm{T}}, \mathrm{X}_{4} \mathrm{Z}_{4}^{\mathrm{T}}\right]\right]^{\mathrm{T}} \\
& \operatorname{per}\left[\mathrm{X}_{1}, \mathrm{X}_{2}, \mathrm{X}_{3}, \mathrm{X}_{4}\right]\left[\operatorname{diag}\left[\mathrm{Z}_{1}, \mathrm{Z}_{2}, \mathrm{Z}_{3}, \mathrm{Z}_{4}\right]\right]^{\mathrm{T}}\left[\operatorname{per}\left[\mathrm{Y}_{1}, \mathrm{Y}_{2}, \mathrm{Y}_{3}, \mathrm{Y}_{4}\right]\right]^{\mathrm{T}} \\
& =\operatorname{diag}\left[\mathrm{X}_{4} \mathrm{Z}_{4}^{\mathrm{T}} \mathrm{Y}_{4}^{\mathrm{T}}, \mathrm{X}_{1} \mathrm{Z}_{1}^{\mathrm{T}} \mathrm{Y}_{1}^{\mathrm{T}}, \mathrm{X}_{2} \mathrm{Z}_{2}^{\mathrm{T}} \mathrm{Y}_{2}^{\mathrm{T}}, \mathrm{X}_{3} \mathrm{Z}_{3}^{\mathrm{T}} \mathrm{Y}_{3}^{\mathrm{T}}\right]
\end{aligned}
$$

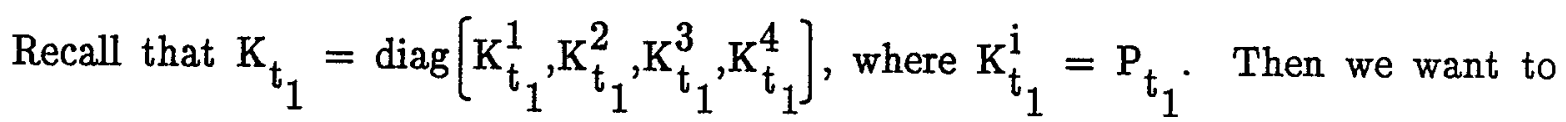
show that $K_{\left(t_{1}-1\right)}$ is zero except on the diagonal, where the $i^{\text {th }}$ block $(i=1,2,3,4)$ is given by

$$
K_{\left(t_{1}-1\right)}^{i}=R_{i}+A_{i}^{T}\left[K_{t_{1}}^{i @ 1}+K_{t}^{i @ 1} B_{i}\left[Q_{i}+B_{i}^{T} K_{t_{1}}^{i @ 1} B_{i}\right]^{-1} B_{i}^{T} K_{t_{1}}^{i @ 1}\right] A_{i}
$$


where @ is the modular addition operator defined by $\mathrm{i} @ \mathrm{k}=\mathrm{m}_{4}(\mathrm{i}+\mathrm{k})$. Furthermore, we require that the block for $i=m_{4}\left(t_{1}-1\right)$ equals the value for $P_{\left(t_{1}-1\right)}$ determined in the solution to problem (1). In other words, $P_{\left(t_{1}-1\right)}$ appears in the $m_{4}\left(t_{1}-1\right)^{\text {st }}$ diagonal block of $\mathrm{K}_{\left(\mathrm{t}_{1}-1\right)}$. The other diagonal blocks of $\mathrm{K}_{\left(\mathrm{t}_{1}-1\right)}$ can be thought of as containing expressions appropriate for the $\mathrm{P}_{\left(t_{1}-1\right)}$ of worlds totally disjoint from ours in which the structure of the economy $\left(R_{t}, Q_{t}, A_{t}\right.$, and $\left.B_{t}\right)$ is translated forward or backward, relative to our own, by 1,2 , or 3 quarters. [The blocks for these parallel worlds contain no information useful in our world, but they are necessary here to maintain the time-invariant nature of problem (A.1), including the convergence of the $\mathrm{P}_{\mathrm{t}-\mathrm{k}}$ sequence to a unique limit as $\mathrm{k} \rightarrow \infty$.] Like $\mathrm{P}_{\left(\mathrm{t}_{1}-1\right)}, \mathrm{K}_{\left(\mathrm{t}_{1}-1\right)}$ is a symmetric negative semidefinite matrix [Bertsekas (1976), p. 72].

To show what we need, I build up an expression for $K_{\left(t_{1}-k\right)}$ from the inside out, starting with the term $B^{T} K_{\left(t_{1}-k+1\right)}$.

$$
\begin{aligned}
& \mathrm{B}^{\mathrm{T}} \mathrm{K}_{\left(\mathrm{t}_{1}-\mathrm{k}+1\right)^{\mathrm{B}}} \\
& =\left[\operatorname{per}\left[\mathrm{B}_{1}, \mathrm{~B}_{2}, \mathrm{~B}_{3}, \mathrm{~B}_{4}\right]\right]^{\mathrm{T}} \operatorname{diag}\left[\mathrm{K}_{\left(\mathrm{t}_{1}-\mathrm{k}+1\right)}^{1}, \mathrm{~K}_{\left(\mathrm{t}_{1}-\mathrm{k}+1\right)}^{2}, \mathrm{~K}_{\left(\mathrm{t}_{1}-\mathrm{k}+1\right)}^{3}, \mathrm{~K}_{\left(\mathrm{t}_{1}-\mathrm{k}+1\right)}^{4}\right] \\
& {\left[\operatorname{per}\left[\mathrm{B}_{1}, \mathrm{~B}_{2}, \mathrm{~B}_{3}, \mathrm{~B}_{4}\right]\right]} \\
& =\left[\operatorname{per}\left[\mathrm{K}_{\left({ }_{1}-k+1\right)}^{2^{T}} \mathrm{~B}_{1}, \mathrm{~K}_{\left(\mathrm{t}_{1}-\mathrm{k}+1\right)}^{3^{\mathrm{T}}} \mathrm{B}_{2}, \mathrm{~K}_{\left(\mathrm{t}_{1}-\mathrm{k}+1\right)}^{4^{\mathrm{T}}} \mathrm{B}_{3}, \mathrm{~K}_{\left({ }_{1}{ }_{1}-\mathrm{k}+1\right)}^{\mathrm{T}} \mathrm{B}_{4}\right)\right]^{\mathrm{T}} \\
& {\left[\operatorname{per}\left[\mathrm{B}_{1}, \mathrm{~B}_{2}, \mathrm{~B}_{3}, \mathrm{~B}_{4}\right]\right]} \\
& =\operatorname{diag}\left[\mathrm{B}_{1}^{\mathrm{T}} \mathrm{K}_{\left(\mathrm{t}_{1}-\mathrm{k}+1\right)}^{2} \mathrm{~B}_{1}, \mathrm{~B}_{2}^{\mathrm{T}} \mathrm{K}_{\left(\mathrm{t}_{1}-\mathrm{k}+1\right)}^{3} \mathrm{~B}_{2}, \mathrm{~B}_{3}^{\mathrm{T}_{3}} \mathrm{~K}_{\left(\mathrm{t}_{1}-\mathrm{k}+1\right)}^{\mathrm{B}_{3}}\right. \text {, } \\
& \left.{ }_{B}^{\mathrm{T}} \mathrm{K}_{\left(\mathrm{t}_{1}-\mathrm{k}+1\right)}^{1} \mathrm{~B}_{4}\right] \text {. }
\end{aligned}
$$


Then

$$
\begin{aligned}
& {\left[Q+B^{T} K_{\left(t_{1}-k+1\right)}\right]^{-1}=\operatorname{diag}\left[\left[Q_{1}+B_{1}^{T_{K}}{ }_{\left(t_{1}-k+1\right)}^{2} B_{1}\right]^{-1}\right.} \\
& {\left[Q_{2}+B_{2}^{T} K_{\left(t_{1}-k+1\right)}^{3} B_{2}\right]^{-1},\left[Q_{3}+B_{3}^{T} K_{\left(t_{1}-k+1\right)}^{4} B_{3}\right]^{-1},} \\
& \left.\left[Q_{4}+B_{4}^{T} K_{\left(t_{1}-k+1\right)}^{1}{ }^{B}\right]^{-1}\right] .
\end{aligned}
$$

Denoting this result as $\operatorname{diag}\left[\Omega_{1}, \Omega_{2}, \Omega_{3}, \Omega_{4}\right]$ and noting that $\Omega_{\mathrm{i}}^{\mathrm{T}}=\Omega_{\mathrm{i}}$, we get

$$
\begin{aligned}
\mathrm{B}\left[\mathrm{Q}+\mathrm{B}^{\mathrm{T}} \mathrm{K}_{\left(\mathrm{t}_{1}-\mathrm{k}+1\right)} \mathrm{B}\right]^{-1} \mathrm{~B}^{\mathrm{T}} \\
=\left[\operatorname{per}\left[\mathrm{B}_{1}, \mathrm{~B}_{2}, \mathrm{~B}_{3}, \mathrm{~B}_{4}\right]\right] \operatorname{diag}\left[\Omega_{1}, \Omega_{2}, \Omega_{3}, \Omega_{4}\right]\left[\operatorname{per}\left[\mathrm{B}_{1}, \mathrm{~B}_{2}, \mathrm{~B}_{3}, \mathrm{~B}_{4}\right]\right]^{\mathrm{T}} \\
=\operatorname{diag}\left[\mathrm{B}_{4} \Omega_{4} \mathrm{~B}_{4}^{\mathrm{T}}, \mathrm{B}_{1} \Omega_{1} \mathrm{~B}_{1}^{\mathrm{T}}, \mathrm{B}_{2} \Omega_{2} \mathrm{~B}_{2}^{\mathrm{T}}, \mathrm{B}_{3} \Omega_{3} \mathrm{~B}_{4}^{\mathrm{T}}\right]
\end{aligned}
$$

Then

$$
\begin{aligned}
& {\left[K_{\left(t_{1}-k+1\right)}+K_{\left(t_{1}-k+1\right)} B\left[Q+B^{T_{K}}{ }_{\left(t_{1}-k+1\right)}\right]^{-1} B_{\left(t_{1}-k+1\right)}\right]} \\
& =\operatorname{diag}\left[K_{\left(t_{1}-k+1\right)}^{1}, K_{\left(t_{1}-k+1\right)}^{2}, K_{\left(t_{1}-k+1\right)}^{3}, K_{\left(t_{1}-k+1\right)}^{4}\right] \\
& +\operatorname{diag}\left[K_{\left(t_{1}-k+1\right)}^{1}, K_{\left(t_{1}-k+1\right)}^{2}, K_{\left(t_{1}-k+1\right)}^{3}, K_{\left(t_{1}-k+1\right)}^{4}\right] \\
& \quad \times \operatorname{diag}\left[B_{4} \Omega_{4} B_{4}^{T}, B_{1} \Omega_{1} B_{1}^{T}, B_{2} \Omega_{2} B_{2}^{T}, B_{3} \Omega_{3} B_{3}^{T}\right] \\
& \quad \times \operatorname{diag}\left[K_{\left(t_{1}-k+1\right)}^{1}, K_{\left(t_{1}-k+1\right)}^{2}, K_{\left(t_{1}-k+1\right)}^{3}, K_{\left(t_{1}-k+1\right)}^{4}\right] \\
& =\operatorname{diag}\left[\Gamma_{1}, \Gamma_{2}, \Gamma_{3}, \Gamma_{4}\right],
\end{aligned}
$$

where

$$
\left.\Gamma_{i}=K_{\left(t_{1}-k+1\right)}^{i}+K_{\left(t_{1}-k+1\right)}^{i} B_{i @ 3} \Omega_{i @ 3} B_{i}^{T} @ 3^{K} t_{1}^{i}-k+1\right),
$$


for $\mathrm{i}=1,2,3,4$, are symmetric matrices.

Then we have

$$
\begin{aligned}
& \dot{\mathrm{K}}_{\left(\mathrm{t}_{1}-\mathrm{k}\right)}=\mathrm{R}+\mathrm{A}^{\mathrm{T}}\left[\mathrm{K}_{\left(\mathrm{t}_{1}-\mathrm{k}+1\right)}+\mathrm{K}_{\left(\mathrm{t}_{1}-\mathrm{k}+1\right)} \mathrm{B}\left[\mathrm{Q}+\mathrm{B}^{\mathrm{T}} \mathrm{K}_{\left(\mathrm{t}_{1}-\mathrm{k}+1\right)} \mathrm{B}\right]^{-1}\right. \\
& \left.B^{\mathrm{T}} \mathrm{K}_{\left(\mathrm{t}_{1}-\mathrm{k}+1\right)}\right]^{\mathrm{A}} \\
& =\operatorname{diag}\left[\mathrm{R}_{1}, \mathrm{R}_{2}, \mathrm{R}_{3}, \mathrm{R}_{4}\right]+\left[\operatorname{per}\left[\mathrm{A}_{1}, \mathrm{~A}_{2}, \mathrm{~A}_{3}, \mathrm{~A}_{4}\right]\right]^{\mathrm{T}} \operatorname{diag}\left[\Gamma_{1}, \Gamma_{2}, \Gamma_{3}, \Gamma_{4}\right] \\
& {\left[\operatorname{per}\left(\mathrm{A}_{1}, \mathrm{~A}_{2}, \mathrm{~A}_{3}, \mathrm{~A}_{4}\right]\right]} \\
& =\operatorname{diag}\left[\mathrm{R}_{1}, \mathrm{R}_{2}, \mathrm{R}_{3}, \mathrm{R}_{4}\right]+\left[\operatorname{per}\left[\Gamma_{2} \mathrm{~A}_{1}, \Gamma_{3} \mathrm{~A}_{2}, \Gamma_{4} \mathrm{~A}_{3}, \Gamma_{1} \mathrm{~A}_{4}\right]\right]^{\mathrm{T}} \operatorname{per}\left[\mathrm{A}_{1}, \mathrm{~A}_{2}, \mathrm{~A}_{3}, \mathrm{~A}_{4}\right] \\
& =\operatorname{diag}\left[\left[\mathrm{R}_{1}+\mathrm{A}_{1}^{\mathrm{T}} \Gamma_{2} \mathrm{~A}_{1}\right],\left[\mathrm{R}_{2}+\mathrm{A}_{2}^{\mathrm{T}} \Gamma_{3} \mathrm{~A}_{2}\right],\left[\mathrm{R}_{3}+\mathrm{A}_{3}^{\mathrm{T}} \Gamma_{4} \mathrm{~A}_{3}\right],\left[\mathrm{R}_{4}+\mathrm{A}_{4}^{\mathrm{T}} \Gamma_{1} \mathrm{~A}_{4}\right]\right] \\
& =\operatorname{diag}\left[\left\{R_{1}+A_{1}^{T}\left[K_{\left(t_{1}-k+1\right)}^{2}+K_{\left(t_{1}-k+1\right)}^{2} B_{1}\left[Q_{1}+B_{1}^{T} K_{\left(t_{1}-k+1\right)}^{2} B_{1}\right]^{-1}\right.\right.\right. \\
& \left.\left.\mathrm{B}_{1}^{\mathrm{T}} \mathrm{K}_{\left(\mathrm{t}_{1}-\mathrm{k}+1\right)}^{2}\right] \mathrm{~A}_{1}\right\},\left\{\mathrm{R}_{2}+\mathrm{A}_{2}^{\mathrm{T}}\left[\mathrm{K}_{\left(\mathrm{t}_{1}-\mathrm{k}+1\right)}^{3}+\mathrm{K}_{\left(\mathrm{t}_{1}-\mathrm{k}+1\right)}^{3} \mathrm{~B}_{2}\right.\right. \\
& \left.\left.\left[\mathrm{Q}_{2}+\mathrm{B}_{2}^{\mathrm{T}} \mathrm{K}_{\left(\mathrm{t}_{1}-\mathrm{k}+1\right)}^{3} \mathrm{~B}_{2}\right]^{-1} \mathrm{~B}_{2}^{\mathrm{T}} \mathrm{K}_{\left(\mathrm{t}_{1}-\mathrm{k}+1\right)}^{3}\right] \mathrm{~A}_{2}\right\} \text {, } \\
& \left\{\mathrm{R}_{3}+\mathrm{A}_{3}^{\mathrm{T}}\left[\mathrm{K}_{\left(\mathrm{t}_{1}-\mathrm{k}+1\right)}^{4}+\mathrm{K}_{\left(\mathrm{t}_{1}-\mathrm{k}+1\right)}^{4} \mathrm{~B}_{3}\left[\mathrm{Q}_{3}+\mathrm{B}_{3}^{\mathrm{T}} \mathrm{K}_{\left(\mathrm{t}_{1}-\mathrm{k}+1\right)}^{4} \mathrm{~B}_{3}\right]^{-1}\right.\right. \\
& \left.\left.\mathrm{B}_{3}^{\mathrm{T}} \mathrm{K}_{\left(\mathrm{t}_{1}-\mathrm{k}+1\right)}^{4}\right] \mathrm{~A}_{3}\right\},\left\{\mathrm{R}_{4}+\mathrm{A}_{4}^{\mathrm{T}}\left[\mathrm{K}_{\left(\mathrm{t}_{1}-\mathrm{k}+1\right)}^{1}+\mathrm{K}_{\left(\mathrm{t}_{1}-\mathrm{k}+1\right)}^{1} \mathrm{~B}_{4}\right.\right. \\
& \left.\left.\left.\left[\mathrm{Q}_{4}+\mathrm{B}_{4}^{\mathrm{T}} \mathrm{K}_{\left(\mathrm{t}_{1}-\mathrm{k}+1\right)}^{1} \mathrm{~B}_{4}\right]^{-1} \mathrm{~B}_{4}^{\mathrm{T}} \mathrm{K}_{\left(\mathrm{t}_{1}-\mathrm{k}+1\right)}\right] \mathrm{A}_{4}\right\}\right] \text {. }
\end{aligned}
$$

Inspection of this result for the case $\mathrm{k}=1$ shows that $\mathrm{K}_{\left(\mathrm{t}_{1}-1\right)}$ has the structure we require.

Now assume that $P_{\left(t_{1}-k+1\right)}$ appears in the $m_{4}\left(t_{1}-k+1\right)^{\text {st }}$ diagonal block of $\mathrm{K}_{\left(\mathrm{t}_{1}-\mathrm{k}+1\right)}$, that the other diagonal blocks contain symmetric negative semidefinite 
matrices, and that the rest of $\mathrm{K}_{\left(\mathrm{t}_{1}-\mathrm{k}+1\right)}$ is zero. The arguments presented above hold again and show that $\mathrm{K}_{\left(\mathrm{t}_{1}-\mathrm{k}\right)}$ is zero except on the diagonal, where the $\mathrm{i}^{\text {th }}$ block ( $\mathrm{i}=1,2$, 3,4, ) is given by

$$
\begin{aligned}
K_{\left(t_{1}-k\right)}^{i}=R_{i}+ & A_{i}^{T}\left[K_{\left(t_{1}-k+1\right)}^{i @ 1}+K_{\left(t_{1}-k+1\right)}^{i @ 1} B_{i}\right. \\
& {\left.\left.\left[Q_{i}+B_{i}^{T} K_{\left({ }_{1}-k+1\right)}^{i @ 1}\right]^{B_{i}}\right)^{-1} B_{i}^{T} K_{\left(t_{1}-k+1\right)}^{i @ 1}\right] A_{i} . }
\end{aligned}
$$

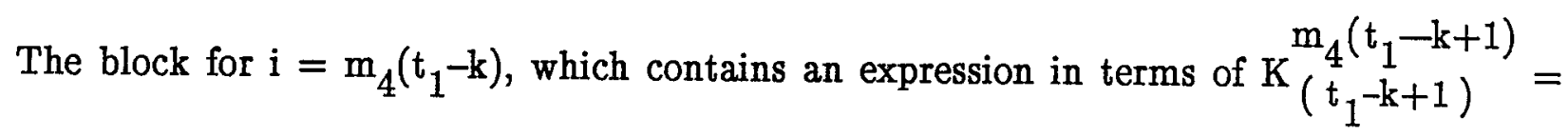
$\mathrm{P}_{\left(\mathrm{t}_{1}-\mathrm{k}+1\right)}$, is equivalent to $\mathrm{P}_{\left(\mathrm{t}_{1}-\mathrm{k}\right)}$ from problem (1). Thus, $\mathrm{K}_{\left(\mathrm{t}_{1}-\mathrm{k}\right)}$ is a symmetric negative semidefinite matrix with zeros everywhere except in its diagonal blocks, and its $\mathrm{m}_{4}\left(\mathrm{t}_{1}-\mathrm{k}\right)^{\text {th }}$ diagonal block contains $\mathrm{P}_{\left(\mathrm{t}_{1}-\mathrm{k}\right)}$.

A subset of the calculations performed in the inductive matching of $K_{\left(t_{1}-k\right)}$ with $P_{\left(t_{1}-k\right)}$ matches $L_{\left(t_{1}-k\right)}$ with $F_{\left(t_{1}-k\right)}$ in a similar fashion. That is, $L_{\left(t_{1}-k\right)}$ is zero except in its diagonal blocks, and the $\mathrm{m}_{4}\left(\mathrm{t}_{1}-\mathrm{k}\right)^{\text {th }}$ diagonal block contains $F_{\left(t_{1}-k\right)}$.

Recall that $\mathrm{x}_{\mathrm{t}_{0}}$ occupies the $\mathrm{m}_{4}\left(\mathrm{t}_{0}\right)^{\text {th }}$ block of the otherwise zero $\mathrm{y}_{\mathrm{t}_{0}}$. Given the structure of $\mathrm{L}_{\left(\mathrm{t}_{1}-\mathrm{k}\right)}$ and the definition of $\mathrm{e}_{\mathrm{s}(\mathrm{t})}$ from equation (A.1b), matrix multiplication shows the following: $u_{t_{0}}$ is zero, except its $m_{4}\left(t_{0}\right)^{\text {th }}$ block contains $v_{t_{0}}$; $y_{t_{0}+1}$ is zero, except its $m_{4}\left(t_{0}+1\right)^{\text {st }}$ block contains $x_{t_{0}+1} ; u_{t_{0}+1}$ is zero, except its $\mathrm{m}_{4}\left(\mathrm{t}_{0}+1\right)^{\text {st }}$ block contains $\mathrm{v}_{\mathrm{t}_{0}+1}$; and so on.

When $e_{s(t)}$ is replaced by the $4 n \times 4 n$ identity matrix, then $x_{t}, y_{t}$, and $v_{t}$ are, in general, nonzero in all their elements. However, only the blocks of these vectors which are nonzero in the system with $\mathrm{e}_{\mathrm{s}(\mathrm{t})}$ defined as before are of interest. Furthermore, the diagonal and periodic structure of the matrices means that the values of these interesting components are unaffected by whether or not the other components are zero. So we are 
free to replace $e_{s(t)}$ by an identity matrix and to ignore the components of $x, y$, and $v$ corresponding to the parallel universes discussed above.

In summary, all of the information obtained by solving the PLQ problem in the lower-dimensional time-varying form of problem (1) also can be obtained by reading the appropriate blocks of the solution to a higher-dimensional TILQ problem. 


\section{Appendix B}

\section{Convergence theorems for periodic LQ models}

For TILQ problems, economists and systems theorists have extensively studied the conditions sufficient to guarantee convergence, as $k \rightarrow \infty$, of the value matrix $P_{\left(t_{1}-k\right)}$ and the feedback rules $F_{\left(t_{1}-k\right)}$ as well as the nonexplosive behavior of the closed-loop system $\mathrm{x}_{\mathrm{t}+1}=(\mathrm{A}-\mathrm{BF}) \mathrm{x}_{\mathrm{t}}+\xi_{\mathrm{t}+1}$. [See Bertsekas (1976), Kwakernaak and Sivan (1972), and Sargent (1981).] These conditions, which greatly facilitate empirical work on dynamic systems, have been implicitly extended to the PLQ case by the results of Appendix A. Here, in Appendix B, I show some of the special forms the convergence conditions assume for PLQ problems. These forms are useful for directly analyzing the properties of PLQ models without first converting the PLQ models to higher-dimensional TILQ models, which are less efficient numerically. (Readers are referred to the references cited earlier in this paragraph for definitions of the concepts used here and for the standard time-invariant theorems.)

Let's begin by developing a particular controllability canonical form for PLQ problems. A first step is to compute the controllability matrix $P$ for the periodic system (A.1). Matrix multiplication (and reordering of the columns of $P$, which doesn't affect the columns' span) shows that this can be written as

$$
\mathrm{P}=\operatorname{diag}\left[\mathrm{P}_{4}, \mathrm{P}_{1}, \mathrm{P}_{2}, \mathrm{P}_{3}\right]
$$

where

$$
\begin{aligned}
& P_{i}=\left[B_{i}, A_{i} B_{i @ 3}, A_{i} A_{i @ 3} B_{i @ 2}, A_{i} A_{i @ 3} A_{i @ 2} B_{i @ 1}, \overline{A_{i}} B_{i}, \overline{A_{i}} A_{i} B_{i @ 3},\right. \\
& \bar{A}_{i} A_{i} A_{i @ 3} B_{i @ 2}, \bar{A}_{i} A_{i} A_{i @ 3} A_{i @ 2} B_{i @ 1}, \ldots, \bar{A}_{i}^{n-1} B_{i}, \bar{A}_{i}^{n-1} A_{i} B_{i} @ \\
& \left.\bar{A}_{i}^{n-1} A_{i} A_{i @ 3} B_{i @ 2}, \bar{A}_{i}^{n-1} A_{i} A_{i} @ 3^{A_{i} @ 2} B_{i @ 1}\right] \text {, }
\end{aligned}
$$

with 


$$
\bar{A}_{i}=A_{i} A_{i} @ A_{i} @ A^{A} @ 1
$$

and the modular addition operator @ is defined in Appendix A. In effect, each season has its own controllability matrix and hence its own controllable subspace, which I denote as $C_{i}$ (for $\left.i=1,2,3,4\right)$. It is therefore possible that the system can reach a given state in one season but not reach it in another.

The decomposition of the controllable subspace into four orthogonal seasonal components permits the construction of a revealing controllability canonical form for the PLQ problem. Suppose the dimension of $C_{i}$ is $r_{i}$. For each $C_{i}$, choose a basis $f_{1}^{i}, f_{2}^{i}, \ldots, f_{r_{i}}^{i}$ and let $T_{1}^{i}=\left[f_{1}^{i} f_{2}^{i} \ldots f_{r_{i}}^{i}\right]$. Choose vectors $f_{r_{j}+1}^{i}, f_{r_{i}+2}^{i}, \ldots, f_{n}^{i}$ so that $f_{1}^{i}, f_{2}^{i}, \ldots, f_{n}^{i} \operatorname{span} R^{n}$, and let $\mathrm{T}_{2}^{\mathrm{i}}=\left[\mathrm{f}_{\mathrm{r}_{\mathrm{i}}+1}^{\mathrm{i}} \mathrm{f}_{\mathrm{r}_{\mathrm{i}}+2}^{\mathrm{i}} \ldots \mathrm{f}_{\mathrm{n}}^{\mathrm{i}}\right]$. Then form $\mathrm{T}=\left[\mathrm{T}_{1} \mathrm{~T}_{2}\right]$, where $\mathrm{T}_{1}=\operatorname{diag}\left[\mathrm{T}_{1}^{1}, \mathrm{~T}_{1}^{2}, \mathrm{~T}_{1}^{3}, \mathrm{~T}_{1}^{4}\right]$ and $\mathrm{T}_{2}=\operatorname{diag}\left[\mathrm{T}_{2}^{1}, \mathrm{~T}_{2}^{2}, \mathrm{~T}_{2}^{3}, \mathrm{~T}_{2}^{4}\right]$. Using $\mathrm{T}$ to transform the PLQ problem (A.1) to controllability canonical form yields

$$
\begin{aligned}
& \tilde{A}= {\left[\begin{array}{ll}
\tilde{A}^{11} & \tilde{A}^{12} \\
0 & \tilde{A}^{22}
\end{array}\right], \text { with } \tilde{A}^{i j}=\operatorname{per}\left[\tilde{A}_{1}^{i j}, \tilde{A}_{2}^{i j}, \tilde{A}_{3}^{i j}, \tilde{A}_{4}^{i j}\right] } \\
& \tilde{A}_{k}^{11} r_{k} \times r_{k}, \tilde{A}_{k}^{12} r_{k} \times\left(n-r_{k}\right) \text {, and } \tilde{A}_{k}^{22}\left(n-r_{k}\right) \times\left(n-r_{k}\right), k=1,2,3,4 ; \\
& \tilde{B}=\left[\begin{array}{l}
\tilde{B}^{1} \\
0
\end{array}\right], \text { with } \tilde{B}^{1}=\operatorname{per}\left[\tilde{B}_{1}^{1}, \tilde{B}_{2}^{1}, \tilde{B}_{3}^{1}, \tilde{B}_{4}^{1}\right] \text { and } \tilde{B}_{i}^{1} r_{i} \times m, i=1,2,3,4 ; \\
& \tilde{R}=\left[\begin{array}{ll}
\tilde{R}^{11} & \tilde{R}^{12} \\
\tilde{R}^{21} & \tilde{R}^{22}
\end{array}\right], \text { with } \tilde{R}^{i j}=\operatorname{diag}\left[\tilde{R}_{1}^{i j}, \tilde{R}_{2}^{i j}, \tilde{R}_{3}^{i j}, \tilde{R}_{4}^{i j}\right] \\
& \tilde{R}_{k}^{11} r_{k} \times r_{k}, \tilde{R}_{k}^{12} r_{k} \times\left(n-r_{k}\right), \tilde{R}_{k}^{21}=\tilde{R}_{k}^{12 T},
\end{aligned}
$$

and

$$
\tilde{\mathrm{R}}_{\mathrm{k}}^{22}\left(\mathrm{n}-\mathrm{r}_{\mathrm{k}}\right) \times\left(\mathrm{n}-\mathrm{r}_{\mathrm{k}}\right), \mathrm{k}=1,2,3,4
$$


This canonical form shows that the stabilizability of the PLQ problem depends on the stability of $\tilde{A}^{22}$. This can be checked directly, but the following theorem uses the special structure of $\tilde{A}^{22}$ to find a sufficient condition for stabilizability that may be easier to check.

Theorem 1. The matrix $\bar{A}^{22}$ is stable provided any one of the matrices $\bar{A}_{i} \equiv$ $\tilde{\mathrm{A}}_{\dot{\mathrm{i}}}^{22} \tilde{\mathrm{A}}_{\mathrm{i}}^{2} \mathrm{~A}_{3}^{2} \tilde{\mathrm{A}}_{\mathrm{i}}^{22} \tilde{\mathrm{A}}_{\mathrm{i}}^{22} \tilde{\mathrm{I}}_{1}(\mathrm{i}=1,2,3,4)$ is stable.

Proof. Let $\lambda$ be any nonzero eigenvalue of $\tilde{A}^{22}$ and partition its eigenvector y as $y=$ $\left[\mathrm{y}_{1}^{\mathrm{T}} \mathrm{y}_{2}^{\mathrm{T}} \mathrm{y}_{3}^{\mathrm{T}} \mathrm{y}_{4}^{\mathrm{T}}\right]^{\mathrm{T}}$, where $\mathrm{y}_{\mathrm{i}}$ is $\left(\mathrm{n}-\mathrm{r}_{\mathrm{i}}\right) \times 1$, with $\mathrm{r}_{\mathrm{i}}$ the dimension of the $\mathrm{i}^{\text {th }}$ controllability subspace. Then $\tilde{\mathrm{A}}^{22 \mathrm{y}}=\lambda \mathrm{y}$, or

$$
\left[\begin{array}{cccc}
0 & 0 & 0 & \tilde{\mathrm{A}}_{4}^{22} \\
\tilde{\mathrm{A}}_{1}^{22} & 0 & 0 & 0 \\
0 & \tilde{\mathrm{A}}_{2}^{22} & 0 & 0 \\
0 & 0 & \tilde{\mathrm{A}}_{3}^{22} & 0
\end{array}\right]\left[\begin{array}{l}
\mathrm{y}_{1} \\
\mathrm{y}_{2} \\
\mathrm{y}_{3} \\
\mathrm{y}_{4}
\end{array}\right]=\left[\begin{array}{l}
\tilde{\mathrm{A}}_{4}^{22} \mathrm{y}_{4} \\
\tilde{\mathrm{A}}_{1}^{22} \mathrm{y}_{1} \\
\tilde{\mathrm{A}}_{2}^{22} \mathrm{y}_{2} \\
\tilde{\mathrm{A}}_{3}^{22} \mathrm{y}_{3}
\end{array}\right]=\left[\begin{array}{c}
\lambda \mathrm{y}_{1} \\
\lambda \mathrm{y}_{2} \\
\lambda \mathrm{y}_{3} \\
\lambda \mathrm{y}_{4}
\end{array}\right] .
$$

By definition, $\mathrm{y} \neq 0$. Suppose $\mathrm{y}_{4}=0$. Then $\tilde{\mathrm{A}}_{4}^{22} \mathrm{y}_{4}=\lambda \mathrm{y}_{1}=0$, or $\mathrm{y}_{1}=0$. This, in turn, implies $\mathrm{y}_{2}=\mathrm{y}_{3}=0$, or $\mathrm{y}=0$, a contradiction. So $\mathrm{y}_{4} \neq 0$, and by similar reasoning $\mathrm{y}_{1}$, $\mathrm{y}_{2}$, and $\mathrm{y}_{3}$ are also nonzero.

Note that $\left(\tilde{\mathrm{A}}^{22}\right)^{4}=\operatorname{diag}\left[\overline{\mathrm{A}}_{4}, \overline{\mathrm{A}}_{1}, \overline{\mathrm{A}}_{2}, \overline{\mathrm{A}}_{3}\right]$ and that $\left(\tilde{\mathrm{A}}^{22}\right)^{4} \mathrm{y}=\lambda^{4} \mathrm{y}$. Thus $\lambda^{4}$ is an eigenvalue of $\left(\tilde{\mathrm{A}}^{22}\right)^{4}$, still with eigenvector $\mathrm{y}$. Writing out $\left(\tilde{\mathrm{A}}^{22}\right)^{4} \mathrm{y}$ and $\lambda^{4} \mathrm{y}$ shows that $\bar{A}_{i} y_{i @ 1}=\lambda^{4} y_{i @ 1}(i=1,2,3,4)$. Thus, if $\lambda$ is an eigenvalue of $\tilde{A}^{22}$, then $\lambda^{4}$ is an eigenvalue of $\bar{A}_{1}, \bar{A}_{2}, \bar{A}_{3}$, and $\bar{A}_{4}$. If any of these four matrices is stable, then $|\lambda|<1$ and $\tilde{A}^{22}$ is stable. 


\section{References}

Bertsekas, Dimitri P., 1976, Dynamic programming and stochastic control (Academic Press, New York).

Birchenhall, C. R., R. C. Bladen-Hovell, A. P. L. Chui, Denise R. Osborn, and J. P. Smith, 1988, A seasonal model of consumption (typescript) (Department of Economics and Econometrics, University of Manchester).

Christiano, Lawrence J. and Martin Eichenbaum, 1987, Temporal aggregation and structural inference in macroeconomics, Carnegie-Rochester Conference Series on Public Policy 26, 63-130.

Eckstein, Zvi, 1984, A rational expectations model of agricultural supply, Journal of Political Economy 92, 1-19.

Eichenbaum, Martin S., 1984, Rational expectations and the smoothing properties of inventories of finished goods, Journal of Monetary Economics 14, 71-96.

Gersovitz, Mark and James G. MacKinnon, 1978, Seasonality in regression: An application of smoothness priors, Journal of the American Statistical Association 73, 264-73.

Ghysels, Eric, 1987, Seasonal extraction in the presence of feedback, Journal of Business and Economic Statistics 5, 191-94.

Ghysels, Eric, 1988, A study toward a dynamic theory of seasonality for economic time series, Journal of the American Statistical Association 83, 168-72.

Hansen, Lars Peters and Thomas J. Sargent, 1980, Formulating and estimating dynamic linear rational expectations models, Journal of Economic Dynamics and Control 2, $7-46$.

Hansen, Lars Peter and Thomas J. Sargent, 1981, Linear rational expectations models for dynamically interrelated variables, in: Robert E. Lucas, Jr., and Thomas J. Sargent, eds., Rational expectations and econometric practice, Vol. 1 (University of Minnesota Press, Minneapolis). 
Hansen, Lars Peter and Thomas J. Sargent, 1989, Recursive linear models of dynamic economies (manuscript) (Hoover Institution, Stanford University).

Kailath, Thomas, 1980, Linear systems (Prentice-Hall, Englewood Cliffs, NJ).

Kennedy, W. J., Jr., and J. E. Gentle, 1980, Statistical computing (Marcel Dekker, Inc.).

Kinderman, A. J. and J. G. Ramage, 1976, Computer generation of normal random numbers, Journal of the American Statistical Association 71, 893-96.

Kwakernaak, Huibert and Raphael Sivan, 1972, Linear optimal control systems (Wiley-Interscience, New York).

Kydland, Finn E. and Edward C. Prescott, 1982, Time to build and aggregate fluctuations, Econometrica 50, 1345-70.

Lucas, Robert E., Jr., and Edward C. Prescott, 1971, Investment under uncertainty, Econometrica 39, 659-81.

Manuelli, Rodolfo and Thomas J. Sargent, 1988, Models of business cycles: A review essay, Journal of Monetary Economics 22, 523-42.

Miron, Jeffrey A. and Stephen P. Zeldes, 1988, Seasonality, cost shocks, and the production smoothing model of inventories, Econometrica 56, 877-908.

Osborn, Denise R., 1988a, Seasonality and habit persistence in a life cycle model of consumption, Journal of Applied Econometrics 3, 255-66.

Osborn, Denise R., 1988b, The implications of periodically varying coefficients for seasonal time series processes (typescript) (Department of Econometrics and Social Statistics, University of Manchester).

Osborn, Denise R. and Jeremy P. Smith, 1989, The performance of periodic autoregressive models in forecasting seasonal U.K. consumption, Journal of Business and Economic Statistics (forthcoming).

Parzen, Emanuel and Marcello Pagano, 1979, An approach to modeling seasonally stationary time series, Journal of Econometrics 9, 137-53. 
Pesando, James E., 1972, Seasonal variability in distributed lag models, Journal of the American Statistical Association 67, 311-12.

Sargent, Thomas J., 1978a, Estimation of dynamic labor demand schedules under rational expectations, Journal of Political Economy 86, 1009-1044.

Sargent, Thomas J., 1978b, Comments on "Seasonal adjustment and multiple time series analysis" by Kenneth F. Wallis, in: Arnold Zellner, ed., Seasonal analysis of economic time series (U.S. Department of Commerce, Bureau of Census, Economic Research Report, ER-1).

Sargent, Thomas J., 1981, Lecture notes on linear optimal control, filtering, and rational expectations (typescript) (University of Minnesota, Minneapolis).

Sargent, Thomas J., 1987, Macroeconomic theory, 2nd ed. (Academic Press, New York).

Singleton, Kenneth J., 1988, Econometric issues in the analysis of equilibrium business cycle models, Journal of Monetary Economics 21, 361-86.

Todd, Richard M., 1982, Formulating dynamic linear rational expectations models by means of periodic-coefficient linear stochastic difference equations (Research Department Working Paper 206, Federal Reserve Bank of Minneapolis).

Todd, Richard M., 1983, A dynamic equilibrium model of seasonal and cyclical fluctuations in the corn-soybean-hog sector (Ph.D. dissertation) (University of Minnesota, St. Paul).

Todd, Richard M., 1987, Links between structural and reduced form seasonality (Research Department Working Paper 330, Federal Reserve Bank of Minneapolis).

Trivedi, P. K. and B. M. S. Lee, 1981, Seasonal variability in a distributed lag model, Review of Economic Studies 48, 497-505. 


\section{Figure Legends}

Fig. 1. 128 observations from a quarterly model with seasonal productivity shifts.

Fig. 2. Estimated logged spectra from a quarterly model with seasonal productivity shifts.

Fig. 3. Response of input use to a unit shock to the exogenous component of output price: True seasonal responses $(-)$ versus response $(---)$ from a time-invariant model estimated with $\mathbf{2 5 5}$ observations from a quarterly model with seasonal productivity shifts: 


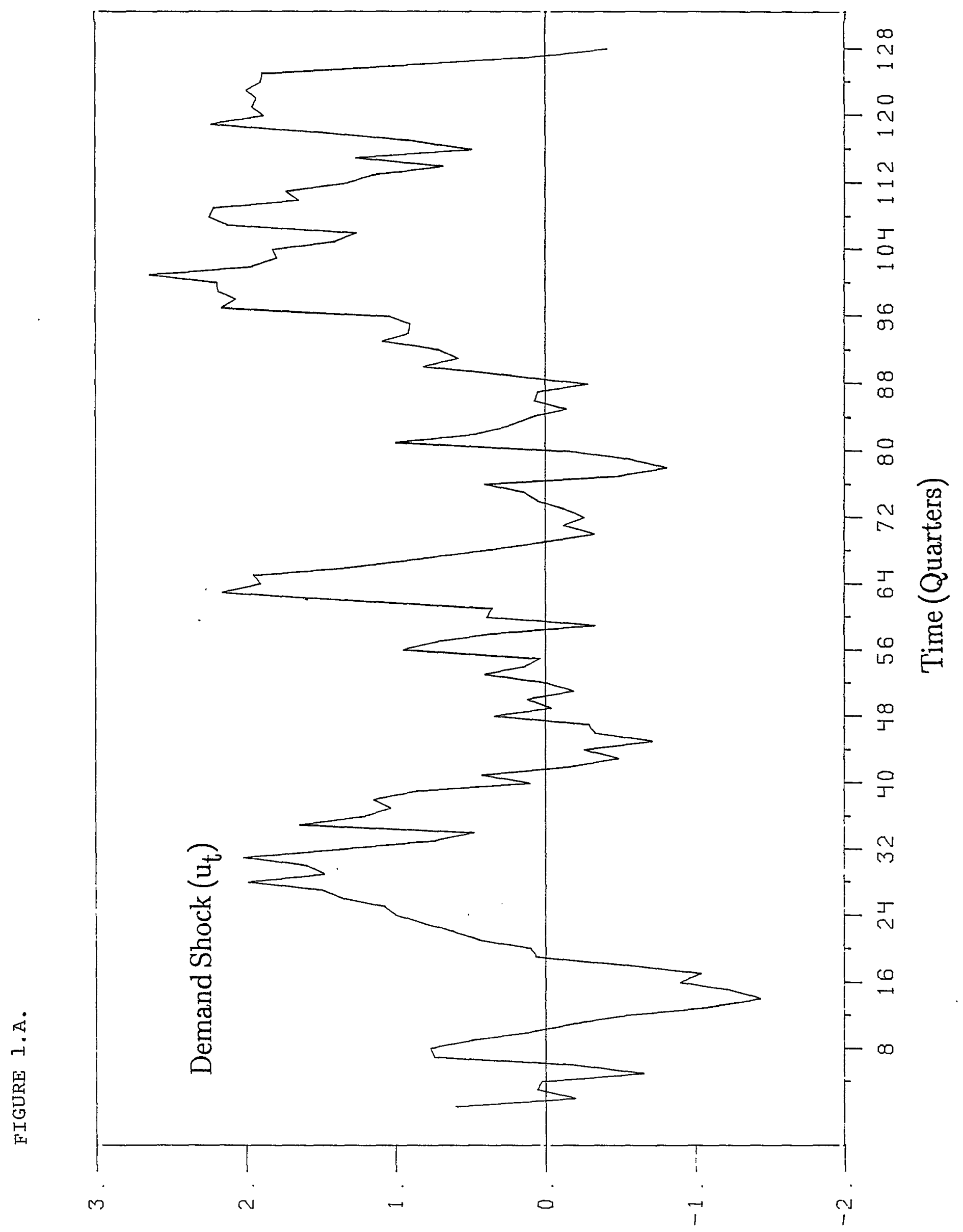




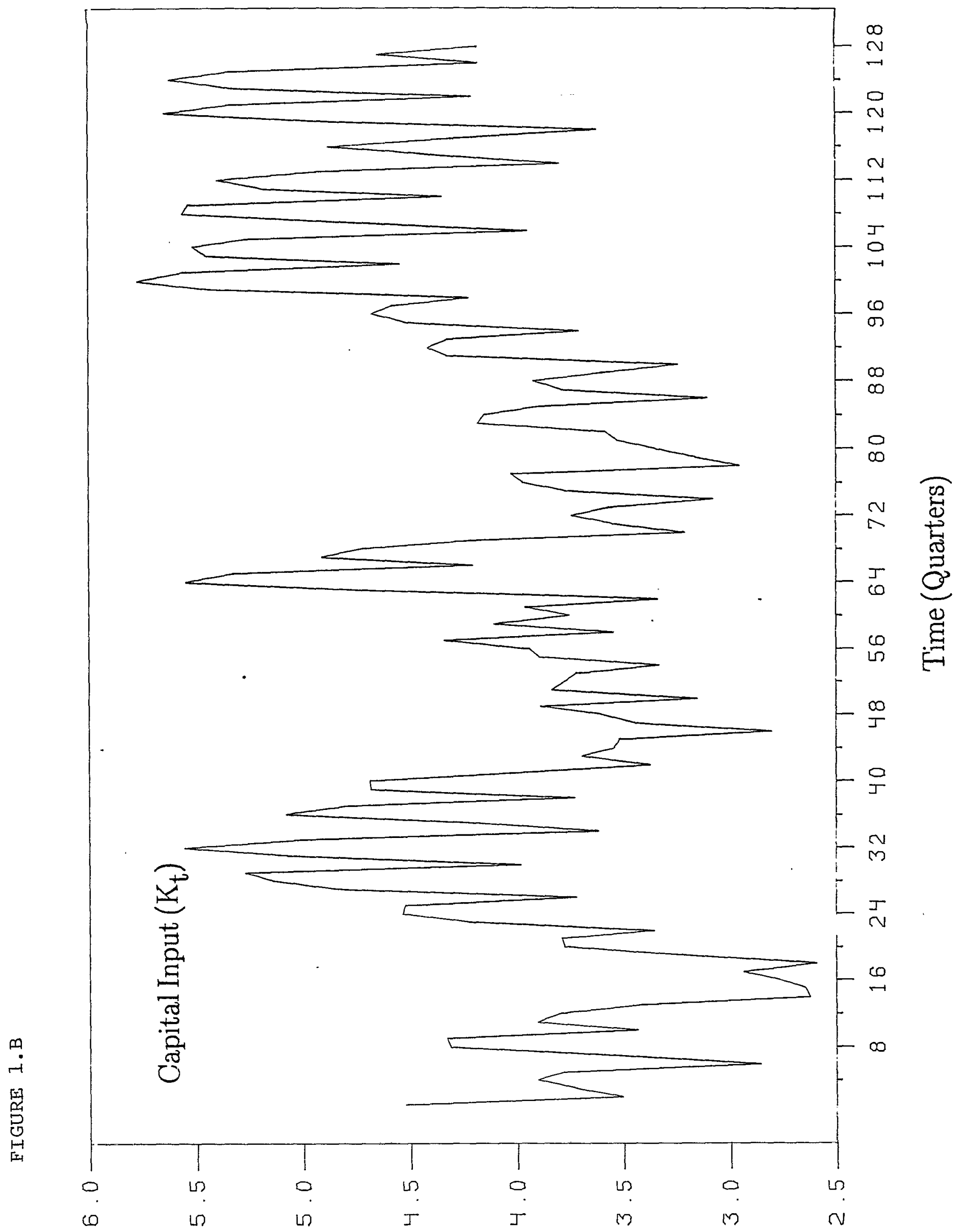




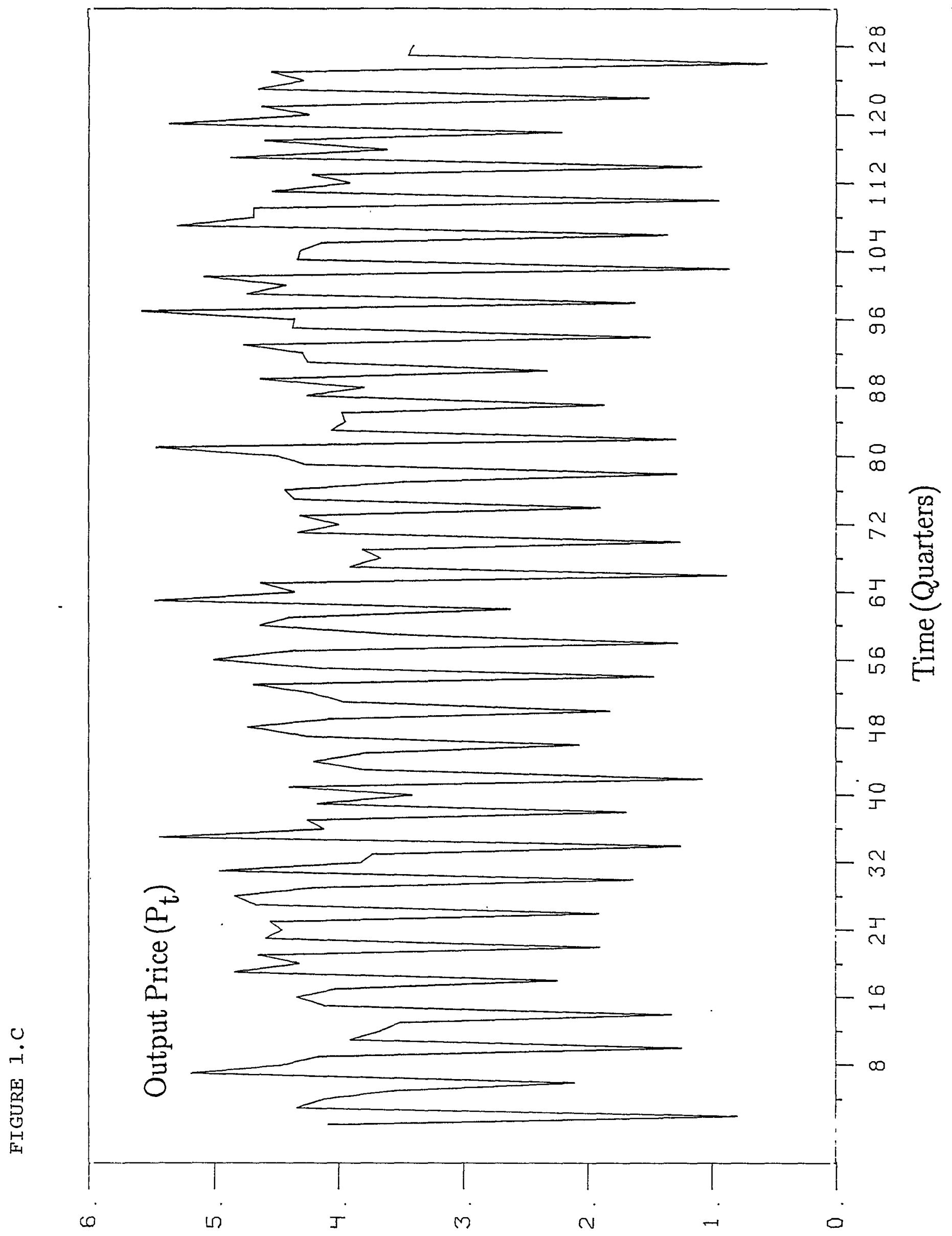




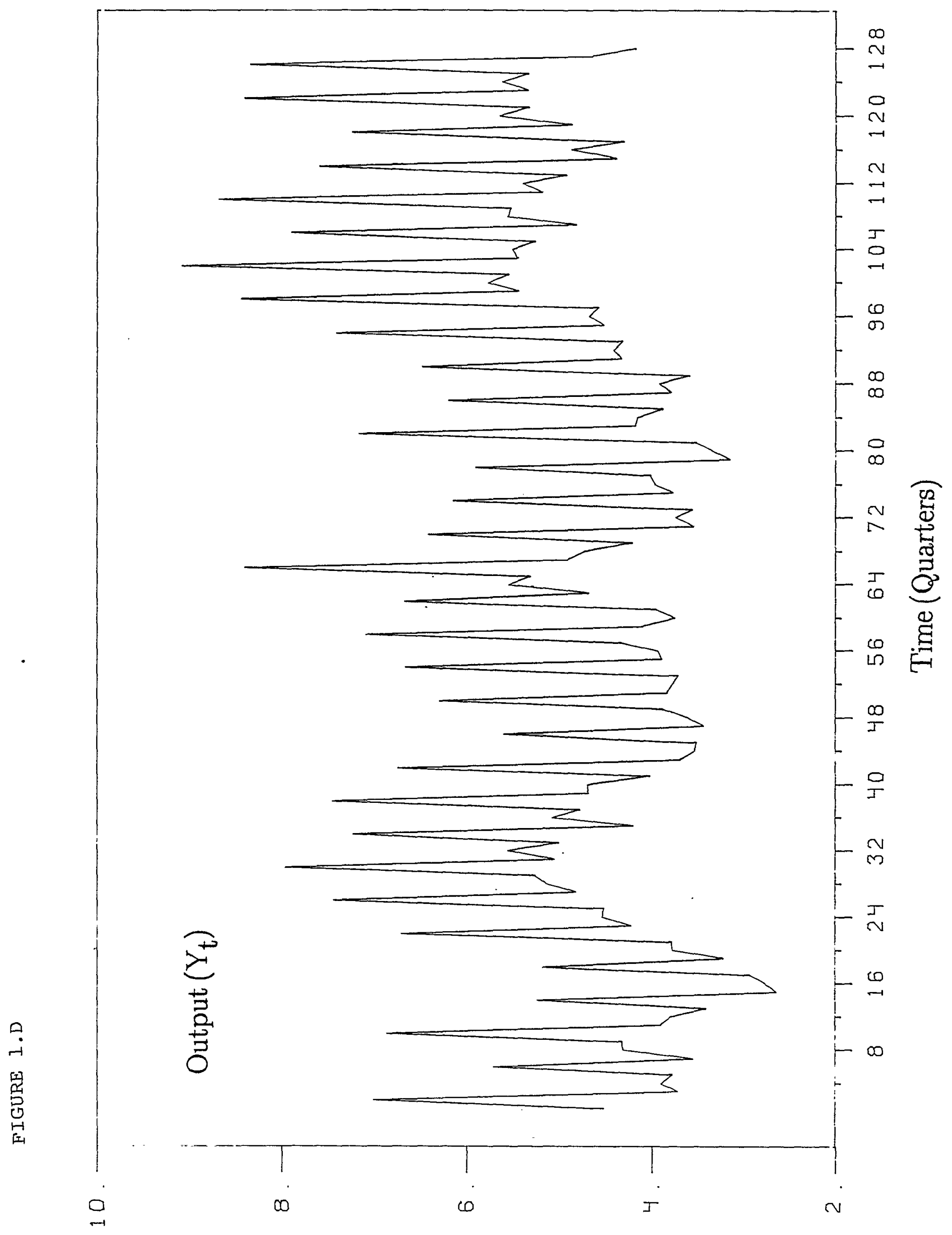




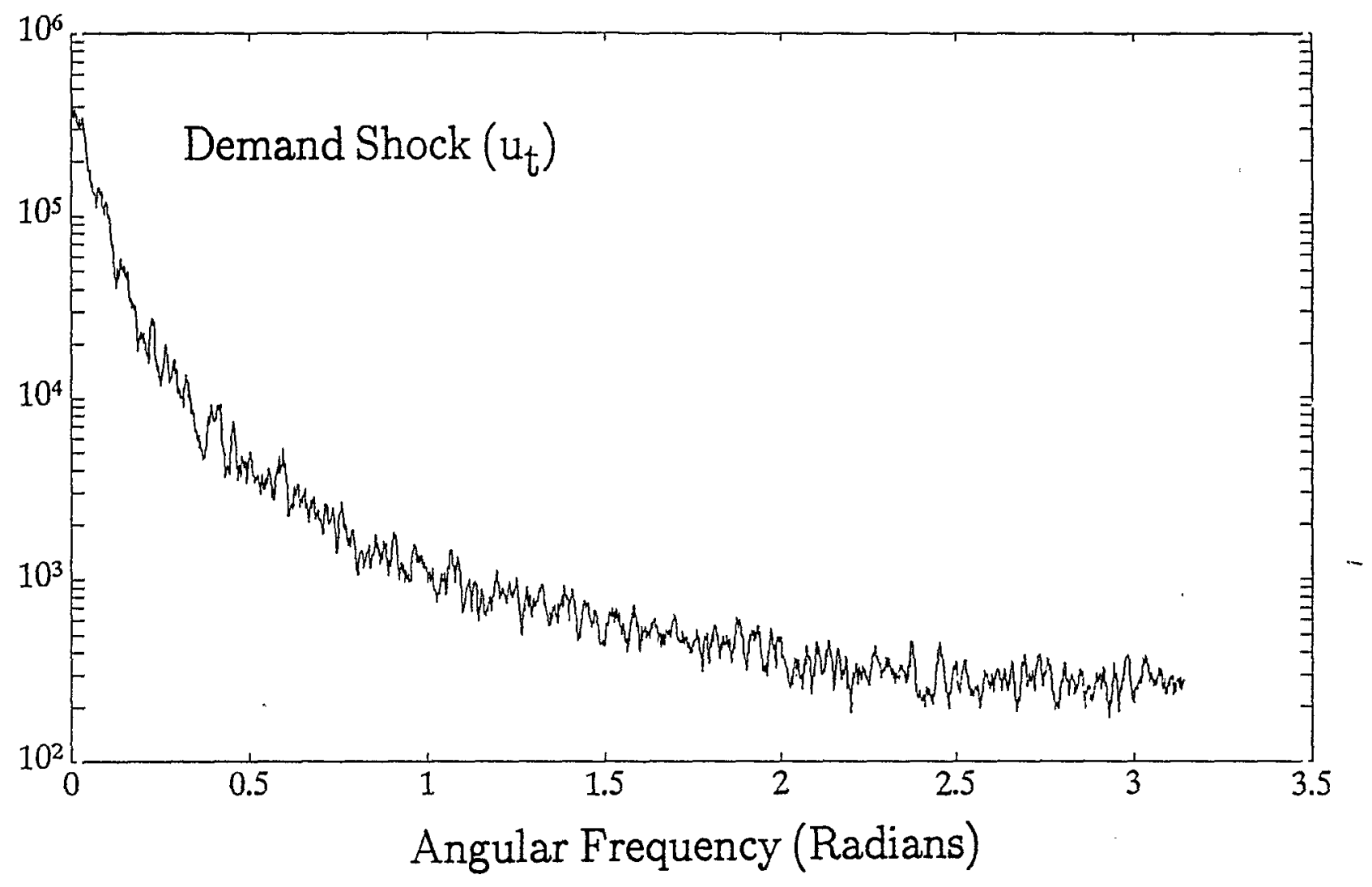

FIGURE 2.A 


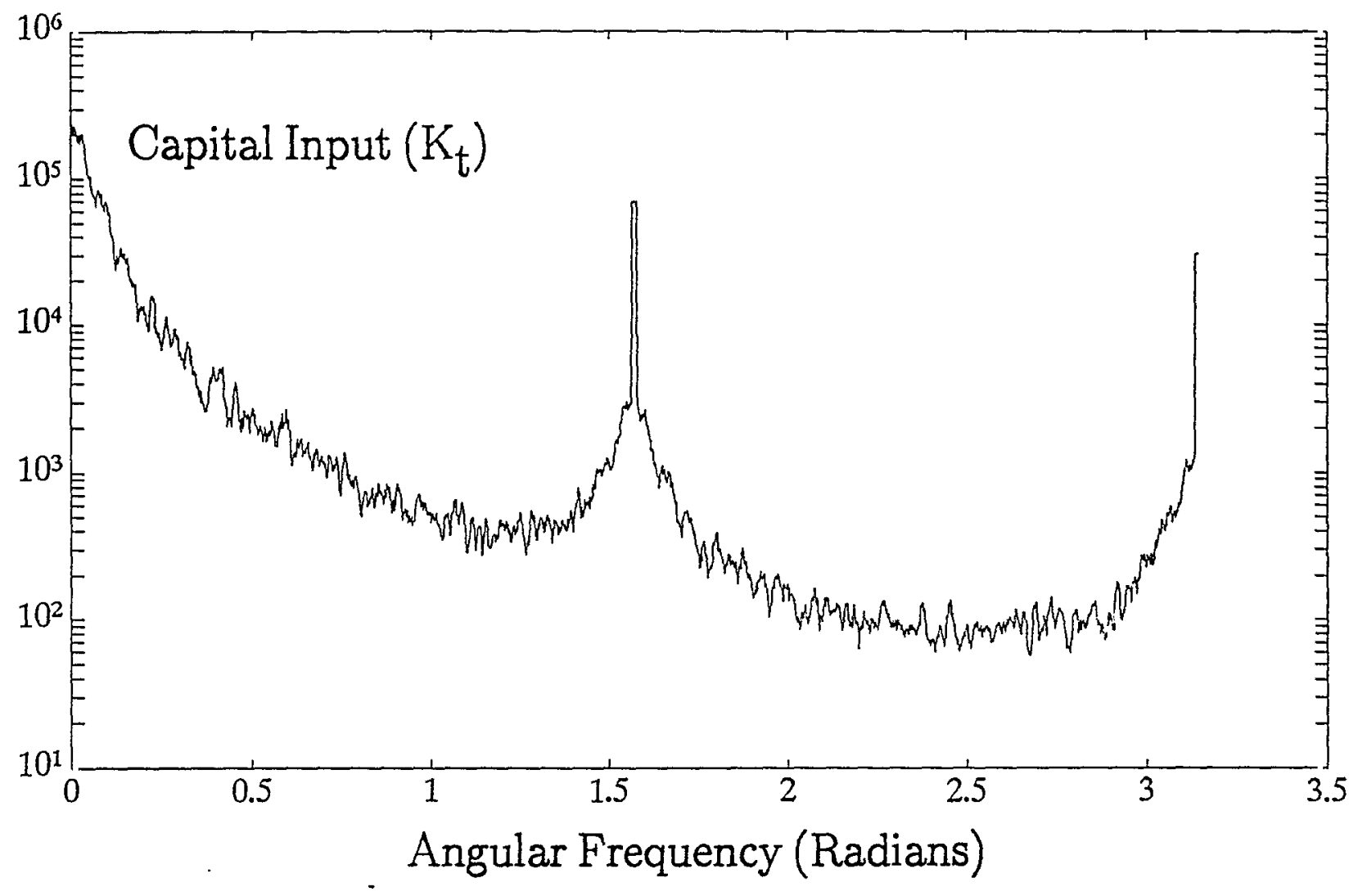

FIGURE 2.B 


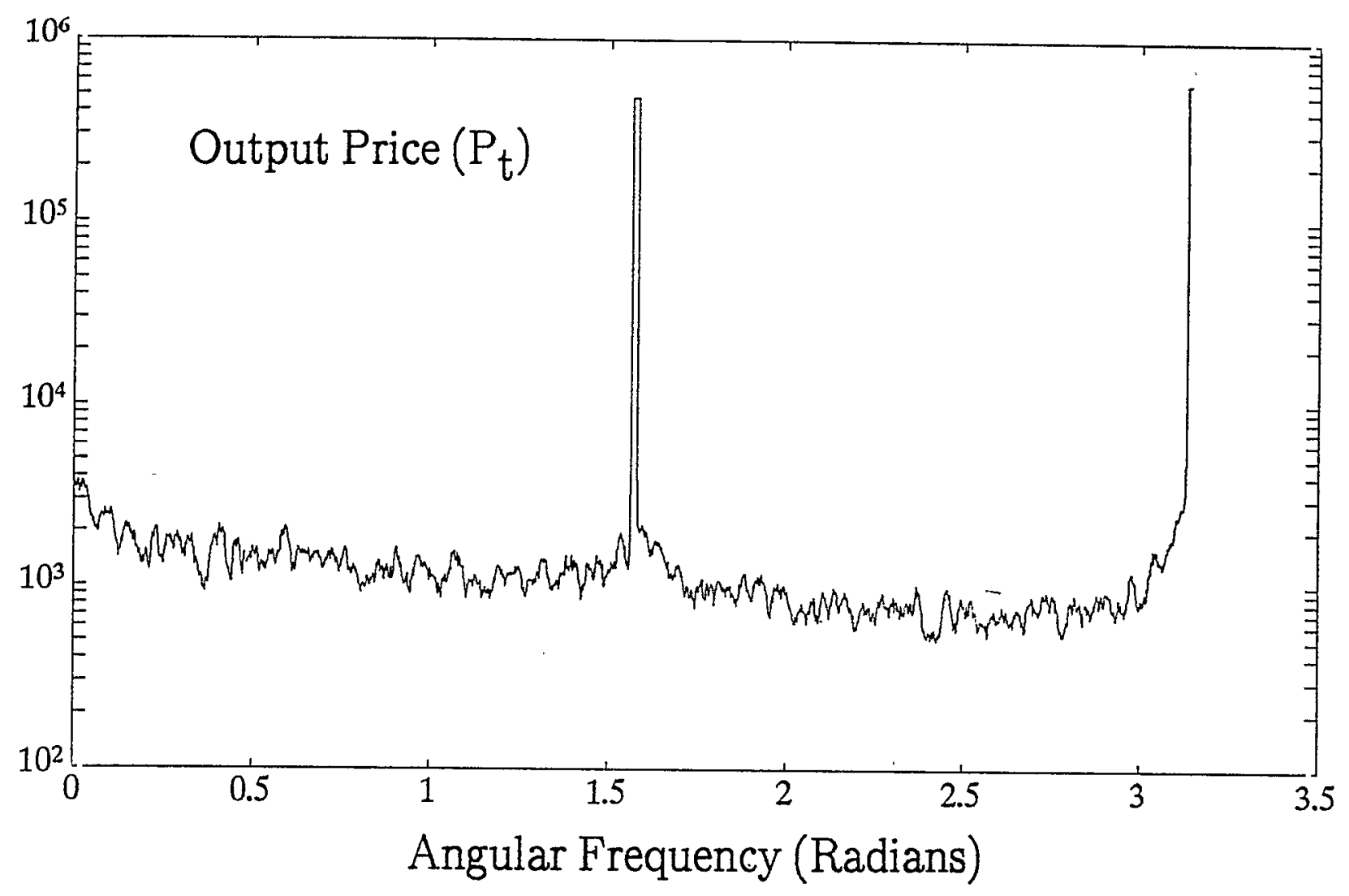

FIGURE 2.C 


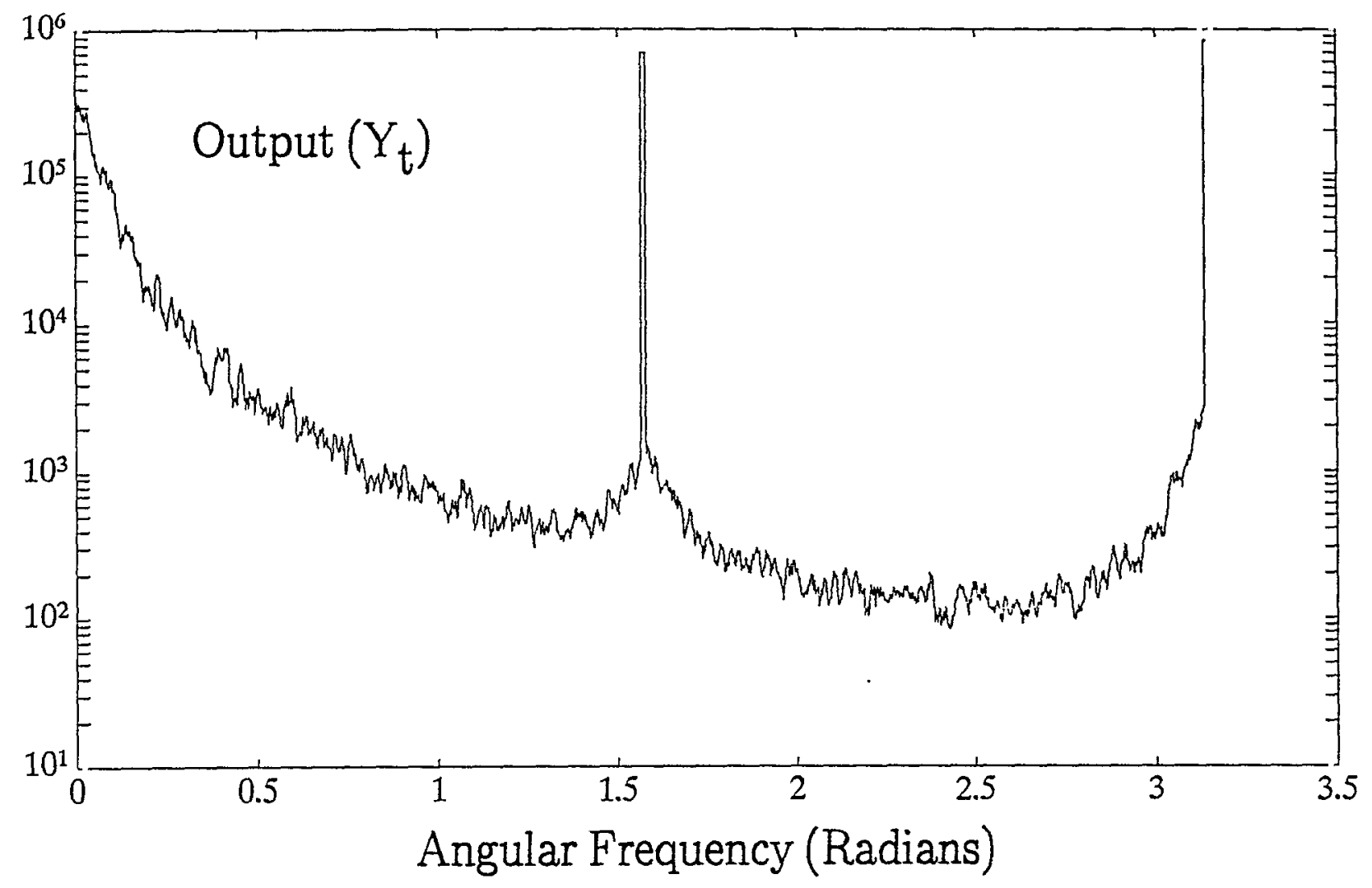

FIGURE 2.D 


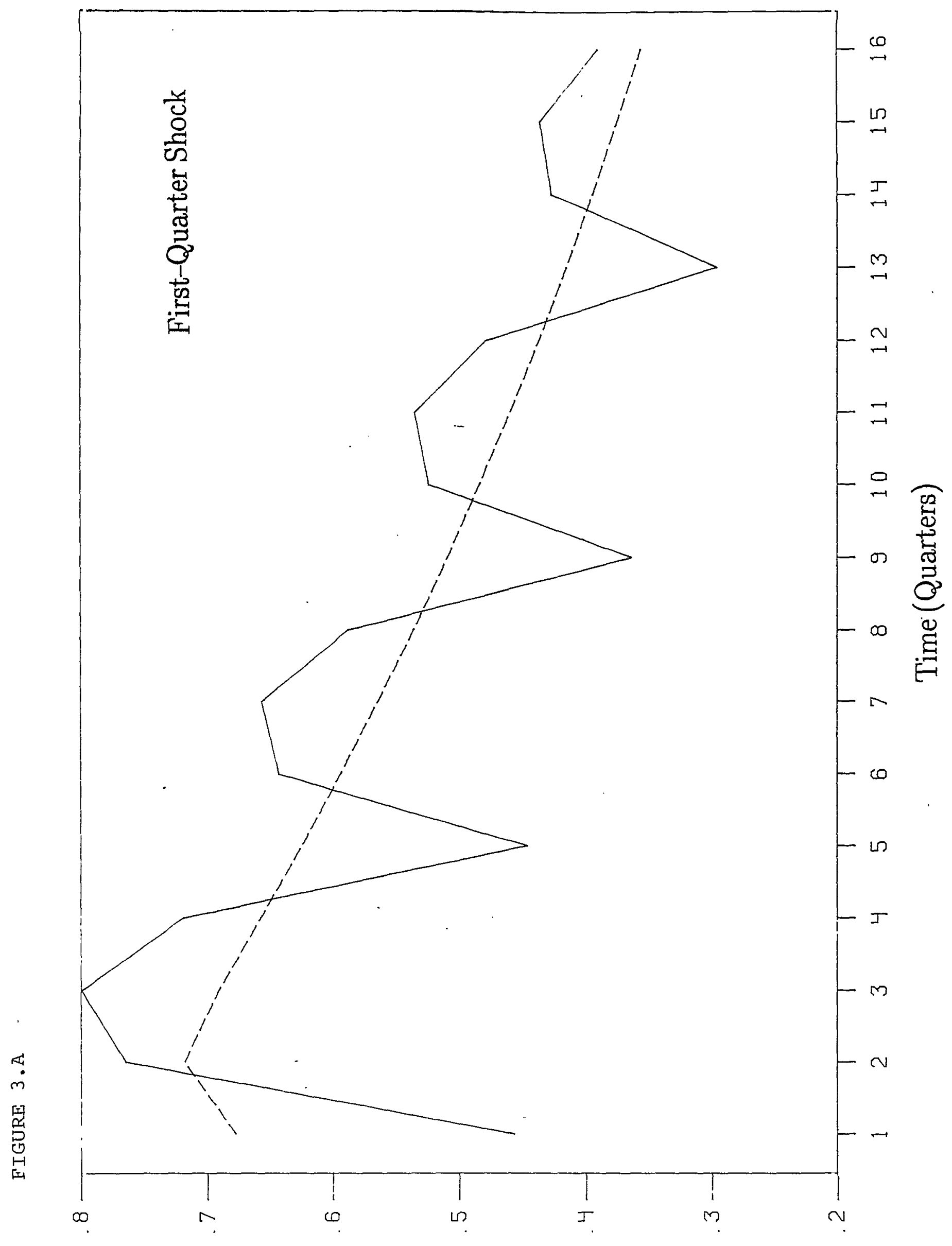




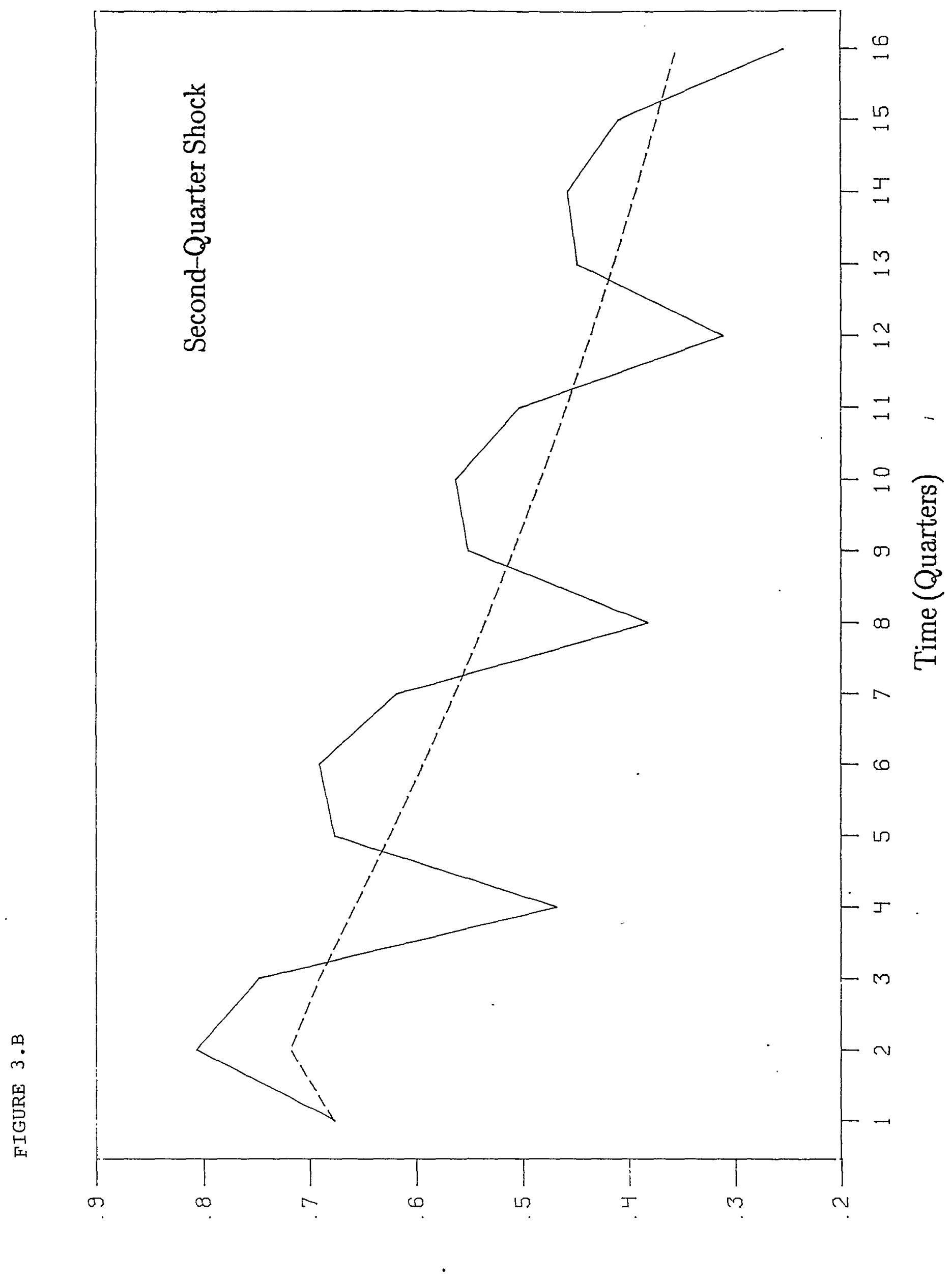




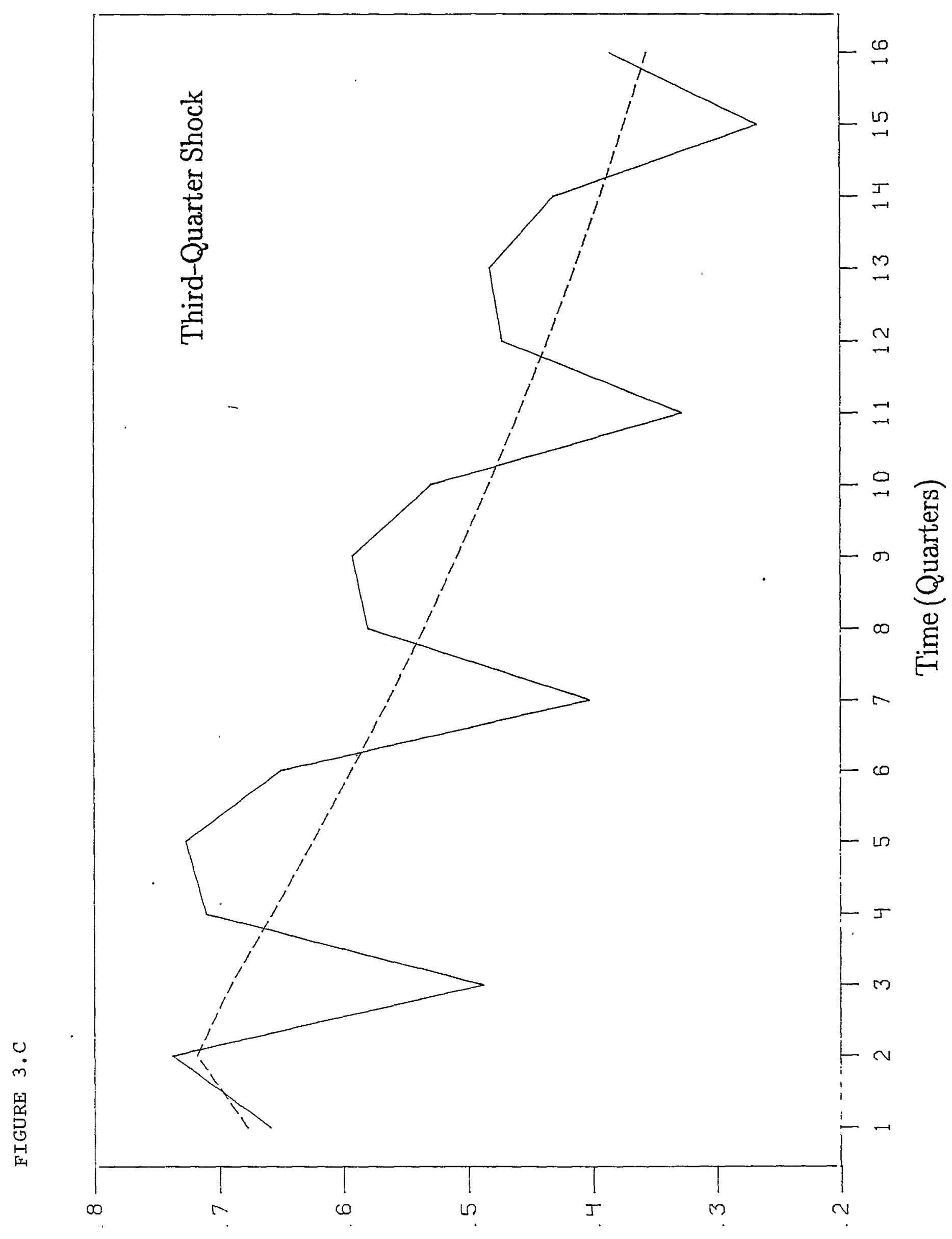




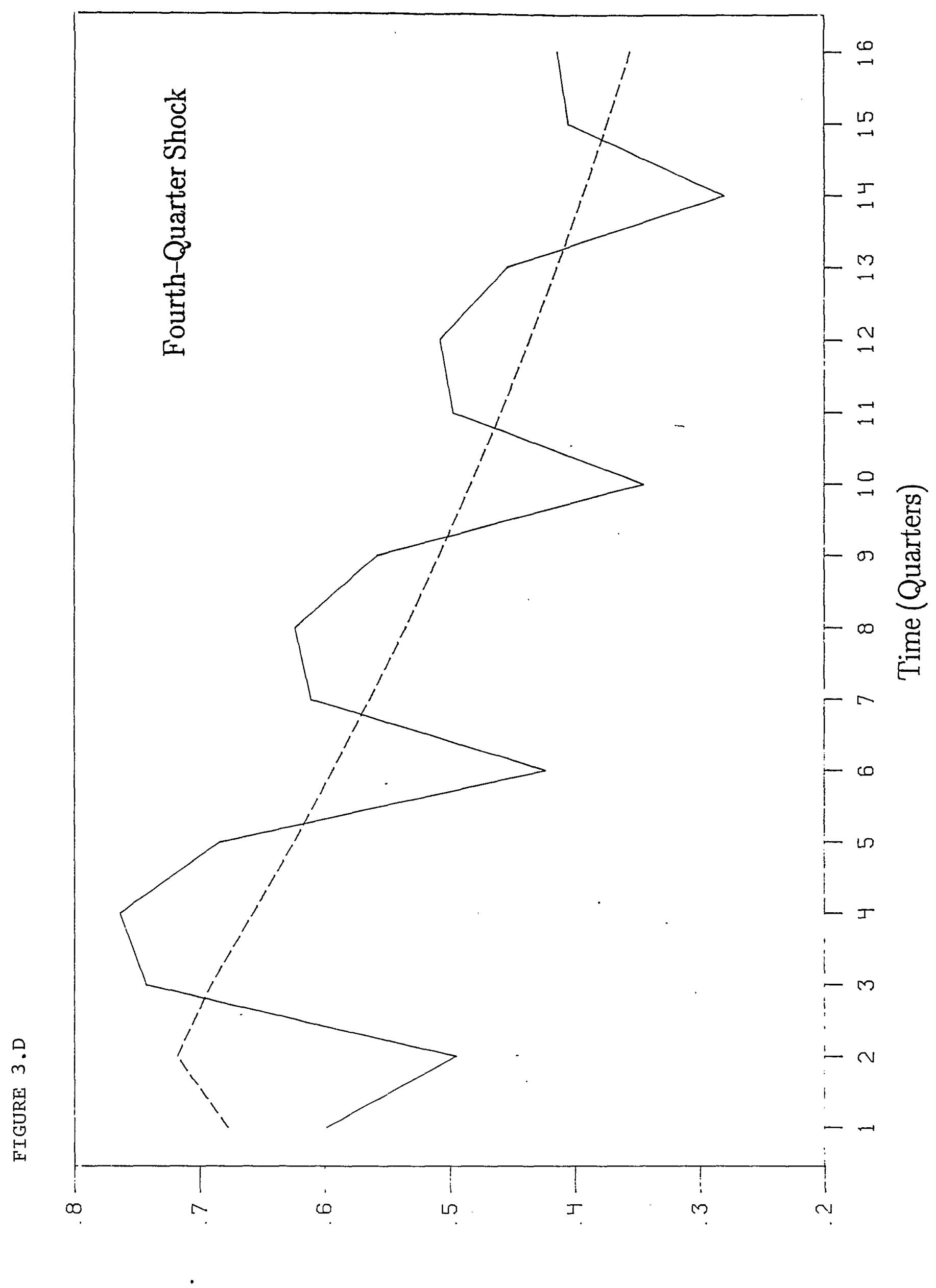

